\title{
QR Obeys Superiority: Frozen Scope and ACD
}

\section{Benjamin Bruening}

The phenomenon of "frozen scope" in double object and spray-load constructions is shown to hold robustly across contexts, constructions, and quantifier types. Nevertheless, frozen scope is not absolute, holding only between two objects but not between an object and a subject or an object and some other operator. The rigidity of two object quantifiers follows the pattern of multiple instances of movement crosslinguistically (multiple $w h$-movement, multiple A-scrambling, multiple object shift): movement paths cross, recreating the hierarchical order of the moving elements (Richards 1997). Hypothesizing that quantifier scope is derived by quantifier-specific syntactic movement, movement that is constrained in the same way as other types of movement, permits these phenomena to be unified under accounts of Relativized Minimality effects generally.

Keywords: quantifiers, scope, double objects, Superiority, Relativized Minimality, covert movement

\section{Introduction: Scope in English}

The facts of quantifier scope interaction in English have motivated claims that the covert raising of quantifiers (QR; May 1977, 1985, and much subsequent work) can change the hierarchical order of quantifiers. Thus, for example, following May (1977), one might generate different readings for the sentence in (1a) by applying QR first to the direct object, as in (1b), or to the object of the preposition, as in (1c). Since adjunction might be thought to create successively higher positions, the quantifier that moves last will take widest scope. In this way (1c) has the surface scope reading, where a different boy is interpreted contextually (i.e., different with respect to some contextually salient boy or set of boys), while (1b) has the inverse scope reading, where boys vary with houses.

(1) a. Jill saw a different boy in each house.

b. [IP each house ${ }_{2}$ [IP a different boy [IP $_{1}$ Jill saw $t_{1}$ in $t_{2}$ ]]]

each $>a$

c. [IP a different boy [IP $_{\text {IP }}$ each house ${ }_{1}\left[\right.$ IP Jill saw $t_{2}$ in $\left.t_{1}\right]$ ]]

$a>$ each

This material has been presented at MIT's Ling-Lunch, Berkeley Linguistics Society 25, the Kanda Move and Interpret Alpha Workshop, and other forums. Thanks are due to the participants there as well as to David Pesetsky, Irene Heim, Kai von Fintel, Sabine Iatridou, Vivian Lin, Lisa Matthewson, Norvin Richards, Uli Sauerland, Calixto AgüeroBautista, Noam Chomsky, Danny Fox, Kyle Johnson, and many others for helpful suggestions and discussion. 
This view of QR is motivated by the fact that scope is generally ambiguous in English, at least in simple cases. Permitting quantifiers to adjoin in any order captures this ambiguity. ${ }^{1}$

Theories of QR have attempted to constrain its application. Fox (1995b), for example, suggests limiting the application of $\mathrm{QR}$ to those instances where raising a quantifier would have some semantic effect. If QR changes scope relations, it is allowed; if it does not, it is not permitted. As Fox shows, this hypothesis correctly accounts for the lack of certain readings in ellipsis constructions (see also Fox 2000). Even with this restriction, however, QR is still expected to reorder quantifiers by moving and adjoining them in any order. In fact, it is expected that the order of quantifiers should be able to change, as this is exactly what would derive a different interpretation - a necessary condition for QR according to Fox's Scope Economy principle. Thus, without additional restrictions we would expect that any quantifier should be able to take scope over any other quantifier in the same clause. ${ }^{2}$

Double object constructions are then mysterious in not permitting the second object to take scope over the first. For instance, each doll in (2a) is unable to take scope over a child. Children cannot vary with dolls in this sentence; there must be a single child receiving all of the dolls. In contrast, scope relations in the dative counterpart of (2a) are entirely free $(2 b)$.

(2) a. I gave a child each doll.

b. I gave a doll to each child.

$$
\begin{aligned}
& a>\text { each, } * e a c h>a \\
& a>\text { each, each }>a
\end{aligned}
$$

The phenomenon illustrated in (2a), dubbed "scope freezing," is problematic for every version of QR. Scope freezing holds not only of the double object construction, but of several related constructions as well - for instance, the spray-load alternation (see Larson 1990, where this observation is credited to David Lebeaux). The facts are laid out in section 2, where scope freezing is shown to hold robustly in these constructions.

Most accounts of scope freezing attribute it to an inability of the second object to move in double object constructions (e.g., Larson 1988, 1990, Aoun and Li 1989, 1993, Marantz 1993). However, section 3 shows that this simplistic view raises a paradox for standard accounts of antecedent-contained deletion (ACD). On closer inspection the paradox is resolved, but this resolution comes from evidence that quantifiers must be able to move even when scope is frozen. Both quantifiers in a double object construction are able to raise out of the VP, but in such a way that

${ }^{1}$ Here and below the discussion will concentrate on the interaction of existential quantifiers (a, some) and the universal quantifiers each and every. Distinctions among quantifiers will be ignored, though on a principled basis: (a) the facts of scope freezing and antecedent-containe d deletion (ACD) indicate that all quantifiers can in principle raise; and (b) despite known differences between each and every (e.g., May 1985, 1988, Beghelli and Stowell 1996), the two behave for present purposes substantially alike. Although each can sometimes take wide scope where every cannot, neither can take wide scope in frozen scope environments (see section 7.2). Similarly, both behave the same in ACD. Therefore, tests for scope given here make use of both universal quantifiers. If one of them can take wide scope, it must be the case that $\mathrm{QR}$ is permitted to change scope relations; if neither can, it is not.

${ }^{2}$ Not all theories that adopt a movement account of scope make this same prediction, for example, those of Aoun and Li (1993), Hornstein (1995), Beghelli and Stowell (1996). However, these run into other problems with the frozen scope data, as discussed in section 7. 
scope remains frozen. That is, movement is unable to reorder quantifiers, contrary to expectation (section 4).

The facts of frozen scope and its behavior in ACD indicate that QR is constrained by much more than Fox's Scope Economy principle: producing a different interpretation is a necessary condition for QR, but is not sufficient to license scope reversals. This article goes even further and argues that frozen scope is not an anomaly, but reveals something fundamental about QR: that it makes use of the same syntactic mechanisms as other movement operations (feature attraction) and is consequently constrained by the same economy conditions. These impose a strict order on derivations by forcing, at every point in a derivation, the application of the most local available instance of a given operation. Formalized as Richards's (1997) Shortest, which subsumes Shortest Attract and Shortest Move, these principles are also responsible for Superiority effects in wh-movement (and other instances of movement). QR is thus argued to be subject to Superiority. Shortest forces QR to move a structurally higher quantifier prior to any lower one and, moreover, forces paths to cross if more than one element moves to the same position, as Richards (1997) has shown to be the case crosslinguistically. For instance, multiple $w h$-movement in languages like Bulgarian recreates the hierarchical order of the moving $w h$-phrases. QR has the same effect on quantifiers, resulting in frozen scope (section 5).

Section 6 motivates a structural difference between double object constructions and their dative counterparts, a difference that will account for scope freezing in the one case but not the other. Finally, section 7 argues that restricting QR in the manner described here is advantageous for two reasons: it unifies QR with all other types of syntactic movement, and it meets the criticism leveled by some recent work against the operation of $\mathrm{QR}$. These proposals argue that a free adjunction operation overgenerates alarmingly. Instead, they treat QR as A-movement, either as an instance of a more general movement for Case reasons (Hornstein 1994, 1995, Pica and Snyder 1994, Kitahara 1996) or as feature-driven movement, applying in different manners to different quantifiers (Beghelli 1996, Beghelli and Stowell 1996). As section 7 shows, both types of approaches fail to account for the facts presented here. The present hypothesis, while similar in spirit, achieves the right empirical coverage, and it does so by restricting the power of QR, thereby meeting the overgeneration criticism.

\section{Frozen Scope}

The lack of ambiguity in double object structures is an exception to the generally free scope interactions characteristic of English. For instance, the dative construction in (3a) is ambiguous, but only surface scope is available in its double object counterpart (3b). The use of different is infelicitous in the latter case and must be interpreted contextually.

(3) a. The teacher gave a (different) book to every student. every $>a$

b. The teacher gave a (\#different) student every book.

*every $>a$

Larson (1990) hypothesizes that the effect in (3b) is an instance of the same phenomenon as that found in the with variant of the spray-load alternation (Hall 1965, Fillmore 1968a,b, 
Anderson 1971, 1977), given in (4b). ${ }^{3}$ Here again only surface scope is available. In contrast, the over alternant is fully ambiguous (4a), just as the dative version of double object verbs is. I will refer to the dative and the nonfrozen variant of the spray-load verbs as the locative variant of these constructions. ${ }^{4}$

(4) a. Maud draped a (different) sheet over every armchair.

b. Maud draped a (\#different) armchair with every sheet.

$\begin{aligned} \text { every } & >a \\ * \text { every } & >a\end{aligned}$

The lack of inverse scope in double object and spray-load constructions is not just a surface phenomenon that holds for certain lexical items, contexts (compare the examples given throughout the text), or types of quantifiers. In addition to the simple scope judgments reported in (3) and (4), three additional tests show that the second object in these constructions is simply unable to take scope over the first. These are (a) the unavailability of pair-list readings in wh-questions, (b) the failure of variable binding, and (c) the lack of a contrast between each and every.

\subsection{Quantifier-Wh Interaction}

May (1985) argues that the mechanism that generates pair-list readings in questions with quantifiers is the same as the mechanism at work in quantifier-quantifier interaction. A pair-list reading arises when the quantifier moves via QR to a position where it can take scope over the wh-word (see also May 1988, Chierchia 1993) or over the trace of the wh-word (Aoun and Li 1993). Quantifier-wh interaction, then, is no different from quantifier-quantifier interaction, and it ought to be subject to the same restrictions. If scope freezing is real, it ought to make itself felt in questions as well.

This is exactly the case. In the locative variants, where scope freezing does not occur, pairlist readings are perfectly available (5). However, in the with variant of the spray-load verbs pairlist readings do not exist (6)..$^{5}$

(5) a. Which sheet did he drape $t$ over every armchair?

b. Which book did you give $t$ to every student?

${ }^{3}$ Levin (1993:50) lists the following verbs as participating in the spray-load alternation: brush, cram, crowd, cultivate, dab, daub, drape, drizzle, dust, hang, heap, inject, jam, load, mound, pack, pile, plant, plaster, ?prick, pump, rub, scatter, seed, settle, sew, shower, slather, smear, smudge, sow, spatter, splash, splatter, spray, spread, sprinkle, spritz, squirt, stack, stick, stock, strew, string, stuff, swab, ?vest, ?wash, wrap.

${ }^{4}$ Prepositions in the locative variants include over, (in)to, in, on. Scope is generally frozen in the with variant, but the preposition in these cases is not always with, as in the clear alternation: I cleared a (\#different) table of each dish. The alternations that show scope freezing include, besides the spray-load alternation, the material/product alternation, the clear alternation, the image impression alternation, the with/against alternation, the through/with alternation, the search alternation, and the body part alternation (names from Levin 1993). Certain nonalternating verbs also show scope freezing, for instance, fill. The unifying factor seems to be that the second object is a theme (Alec Marantz, personal communication); hence, these verbs all fit the characterization of a complex predicate discussed in section 6.

${ }^{5}$ A slight problem arises in attempting to evaluate pair-list readings in the double object construction, since many speakers do not permit extraction of the indirect object. Some varieties of English, however, including mine, allow this extraction in some circumstances (ia). It is possible to test the availability of pair-list readings using people who speak dialects of this sort. The result is a uniform lack of pair-list readings (ib).

(i) a. Which student did you give $t$ the Medal of Excellence?

b. Which student did you give $t$ every book? 
(6) a. Which armchair did he drape $t$ with every sheet? $\quad * P-L$

b. Which wall did he spray $t$ with every color of paint?

Hornstein (1995:115) claims that sentences like those in (5) are unambiguous, arguing that pair-list readings are generated differently from scope ambiguities with two quantifiers. ${ }^{6}$ (Williams (1988) also reports that locative constructions do not have pair-list readings; Stroik (1996) gives the opposite judgment.) Hornstein's example is given in (7).

(7) I know what you gave to everyone for Xmas.

However, I and a majority of the English speakers I have polled find a pair-list reading for (7) perfectly available, though difficult. Examples of the same type presented in a context in which the pair-list reading is salient evoke a unanimous judgment of availability. Consider the following: ${ }^{7}$

(8) At the UN meeting at least one bodyguard was assigned to each diplomat. Some diplomats claimed that they were not assigned enough bodyguards. So now I need to know how many bodyguards the police assigned to each diplomat in order to adjust the figures and avoid the same complaints at the next meeting.

(9) I know that a rival real estate agent showed a different house to each of the buyers that I'm also trying to sell to. I also know that each buyer will buy the house that she considers the best. So now I need to know which house the agent showed to each buyer so that I can show her a better house in each case and make the sale.

All speakers consulted have no difficulty with short texts like those above, indicating that the pair-list reading is available in the locative variant of ditransitives, contra Hornstein. In contrast, adding a felicitous context like those in (8) and (9) does not help the with variant of spray-load verbs (the asterisk indicates infelicity of the reading in the given context). ${ }^{8}$

(10) *In closing the mansion for the duration of my trip to Europe, I had the maids drape a sheet over every armchair. Without thinking, some of them used my expensive damask sheets. So now I need to find out which armchair they draped with each damask sheet so that I can save it from dust and insects.

(11) *I had my workers load a different order of baseball caps onto each truck for shipment in the morning. But someone got mixed up and the trucks got sent to the wrong cities. I have to find out which truck they loaded with each order and get it rerouted to the right place.

\footnotetext{
${ }^{6}$ Thanks to an anonymous $L I$ reviewer for reminding me of this fact.

${ }^{7}$ Thanks to Calixto Agüero-Bautista for discussion of pair-list readings and for suggestions on how to sharpen judgments. Some of the example contexts are his.

${ }^{8}$ Hornstein's claim that pair-list readings are available in double object constructions, thus proving that scope and pair-list readings diverge, is not substantiated by his data. The example he gives is I know what you gave everyone for Xmas. Here the wh-word is the theme and has been extracted from a position below the quantifier. Such constructions are irrelevant to his claim.
} 
Such data support May's contention that quantifier-wh interaction is governed by the same principles as quantifier-quantifier interaction. The contrast also proves the solidity of scope freezing: it is not limited to simple declarative contexts, but carries over to questions as well. The lack of pair-list readings in frozen scope contexts indicates that the second object cannot take scope over the first object, in any syntactic or semantic context.

\subsection{Bound Variables}

Attempting to judge the availability of a scope reading (often a dispreferred one) can be difficult and lead to inconsistent results, although the formulation of a context as above makes judgments much easier. For this reason it can be of great help to investigate bound variable readings as well. If one quantifier is able to take scope over another, the one taking scope should be able to bind a variable contained within the other. This follows from the condition that quantifiers can only bind variables that fall within their scope (Higginbotham 1980, May 1985). In the bound variable test, then, we have another method for deciding the scope of a quantifier.

In the dative construction, a universal quantifier as second object is able to bind a variable inside an existential quantifier that constitutes the first object (12a). Turning to scope-freezing environments, as in (12b) — an example of the double object construction - we see that the bound variable interpretation is ungrammatical. ${ }^{9}$

(12) a. Robert sent a student who'd taken her ${ }_{1}$ course to every professor . $_{1} \quad$ every $>a$

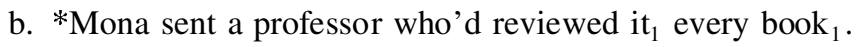

The same judgments appear in the spray-load alternation.

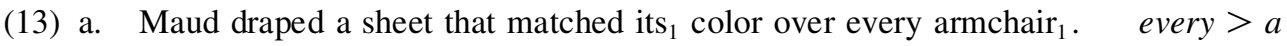

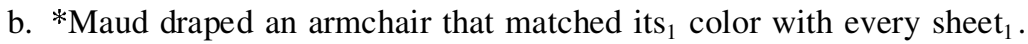

$$
\text { *every }>a
$$

The bound variable test also works in concert with pair-list readings in questions with quantifiers. Both tests converge on the fact that inverse scope is unavailable in double object and spray-load constructions. Variable binding fails in exactly the cases where pair-list readings are unavailable.

(14) a. Which sheet matching its ${ }_{1}$ color did he drape over every $\operatorname{armchair}_{1}$ ? $\quad P-L O K$

b. *Which armchair that matched its ${ }_{1}$ color did he drape with every sheet $_{1}$ ? $* P-L$

\footnotetext{
${ }^{9}$ A potential problem with weak crossover arises here: the configuration derived by raising the lower quantifier above the first is exactly the configuration of weak crossover. However, variable binding in sentences like (12a) is to most English ears fairly grammatical, while where it fails, as in (12b), the sentence is much worse than a weak crossover violation. There seems to be a difference between the pronoun occurring postnominally, as in the text examples, and

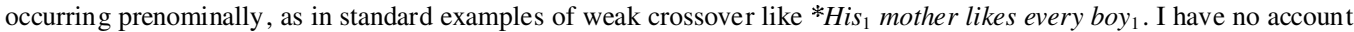
of this contrast (cf. Hornstein's (1995) notion of "almost c-command"), but capitalize on it to construct sentences contrasting in grammaticality.
} 


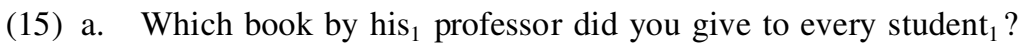

b. *Which student of its ${ }_{1}$ philosophy did you send every book ${ }_{1}$ ?

\subsection{Each versus Every}

It has often been noted that when every is unable to take scope over a wh-phrase, each often can, as in (16) (May 1985, 1988).

(16) a. Which friend brought every present?

b. Which friend brought each present?

In contrast to such pairs, each does not allow a pair-list reading with double object and sprayload verbs. It behaves exactly like every in this respect, as shown in (17a-b) and (18a-b). Each is also prevented from binding a variable in the higher quantifier or $w h$-phrase, as shown in $(17 \mathrm{c}-\mathrm{d})$ and $(18 \mathrm{c}-\mathrm{d})$.

(17) a. Which book did you give $t$ to each student?

$P-L O K$

b. Which student did you give $t$ each book?

c. Which book by his ${ }_{1}$ professor did you give $t$ to each student ${ }_{1}$ ?

$P-L O K$

d. *Which student of its ${ }_{1}$ philosophy did you send $t$ each book b $_{1}$ ?

(18) a. Which sheet did he drape $t$ over each armchair?

b. Which armchair did he drape $t$ with each sheet?

c. Which sheet complementing its ${ }_{1}$ color did he drape $t$ over each armchair $_{1}$ ?

$P-L O K$

d. *Which armchair complementing its ${ }_{1}$ color did he drape $t$ with each sheet ${ }_{1}$ ?

$* P-L$

The facts are then quite simple: the second object in scope-freezing constructions is unable to take scope over the first object. It does not matter whether the second object is each as opposed to every: neither quantifier can take wide scope.

Having established that wide scope for the second object is never available in double object and spray-load constructions, regardless of context or quantifier involved, we turn to a problem that this fact raises for theories of antecedent-contained deletion (ACD). On standard accounts of ACD, movement-specifically, $\mathrm{QR}$ - is what resolves ACD. If frozen scope results from the second object being unable to move, ACD should be ungrammatical. The next section shows that it is not; moreover, closer inspection indicates unequivocally that $\mathrm{QR}$ takes place even though scope is frozen.

\section{ACD}

Antecedent-contained deletion (ACD) is the name given to a variety of ellipsis in which the elided material is contained within its antecedent (Sag 1976; first discussed by Bouton (1970)). In (19a), for example, the ellipsis (indicated by $\Delta$ ) is interpreted as the VP likes to perform in. . . However, if this were the actual antecedent, the sentence would be uninterpretable; it would continue ad infinitum as in (19b). 
(19) a. Nigel likes to perform in every city that David does [VP $\Delta$.

b. Nigel likes to perform in every city that David does [vp likes to perform in every city that David does [VP likes to perform in every city that David does ... ]]

c. [every city that David does $\left[\mathrm{VP}_{\mathrm{P}} \Delta\right]_{\mathrm{x}}$ [Nigel [ $\mathrm{VP}_{\mathrm{P}}$ likes to perform in $\left.\mathrm{x}\right]$ ]

The standard approach to ACD, due to Sag (1976) and developed in May 1985, Larson and May 1990, and Fiengo and May 1994, is to apply QR to the NP hosting the ellipsis, as in (19c). Doing so results in a VP that can serve as an appropriate antecedent for the ellipsis, in this case likes to perform in $x$. Since $\mathrm{QR}$ is independently necessary for the interpretation of quantifiers, this approach is very attractive. Moreover, it predicts that ACD will only be grammatical with an NP that is subject to QR.

This prediction seems to be correct, as the works cited have shown at length. One of the strongest pieces of evidence, as Kennedy (1997) argues, is the fact that the grammaticality of ACD correlates with the availability of wide scope for the quantifier whose movement is necessary to successfully resolve the ellipsis. Thus, in (20) the quantifier whose movement was crucial in (19) can be seen to be able to raise high enough to take scope over the subject.

(20) A different guitarist likes to perform in every city.

every $>a$

Similarly, Sag (1976) and Larson and May (1990) argue that the scope possibilities for a quantifier in an ACD context are restricted by the interpretation of the ellipsis. The quantifier that hosts ACD must take scope over what is interpreted as the antecedent for the ellipsis, as shown, for example, by the lack of de dicto readings with intensional verbs. This will be discussed in detail in section $4.1 .^{10}$

Given this prediction and its broad support, let us ask what happens when ACD is combined with frozen scope. Consider (21) and (22).

(21) a. Ozzy gave someone everything.

*every $>$ some

b. Ozzy gave someone everything that Belinda did [ $\left.v_{\mathrm{p}} \Delta\right]$.

*every $>$ some

(22) a. Cleo wrapped a (\#different) bedpost with every dress. *every $>a$

b. Cleo wrapped a (\#different) bedpost with every dress Chloe did [vP $\Delta]$.

*every $>a$

The result is that ACD is perfectly acceptable, but with the same relative scope between the two objects as in the simple cases in (21a) and (22a) (cf. Larson 1990). This presents a real puzzle, given the correlation between wide scope and the availability of ACD laid out above. One of two outcomes might seem likely: either ACD would simply be ungrammatical, or ACD might suddenly free up scope, since the necessity of QR to resolve ACD might permit a movement that would

${ }^{10}$ It is worth noting that the works cited (especially Kennedy 1997, Fox 1995a, and Pesetsky 2000) have shown that covert movement for the resolution of ACD is crucially phrasal and that quantifier movement cannot be feature movement in the sense of Chomsky 1995. Phrasal movement is implicated in the present analysis and is assumed throughout. 
otherwise not be available. Neither of these is the actual result. ACD is grammatical, but does not change the available scope relations.

The ungrammaticality of bound pronoun readings in ACD further confirms the lack of inverse scope in (23b) and (24b), contrasted with the dative examples in (23a) and (24a).

(23) a. Derrick gave an album she ${ }_{1}$ 'd recorded to every guitarist ${ }_{1}$ Nigel did [vp $\Delta$ ].

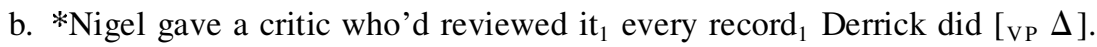

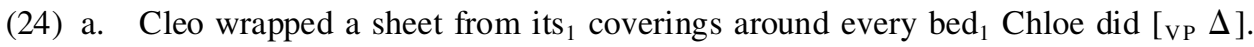

b. *Cleo wrapped a book about its maker with every dress $_{1}$ Chloe did [vp $\left.\Delta\right]$.

Again, the fact that ACD is permitted at all in these constructions is mysterious, given the strong correlation that has been found between the ability of a quantifier to take wide scope and the possibility of ACD.

One way to resolve this paradox is to conclude from these examples that both quantified objects must be moving, but in such a manner as to leave their relative scope unchanged. This would be quite a striking finding: if movement is available, one would expect it to be able to change scopal relations, given the conception of $\mathrm{QR}$ as a generally free and unordered operation. Furthermore, one would expect QR to force a change in scope, if Fox's (1995b) Scope Economy principle is correct.

I will argue that, in spite of expectations, both quantifiers necessarily move, but are unable to reverse their hierarchical order. The next section provides evidence that movement does in fact take place even when scope is frozen. In collecting the evidence that quantifiers whose scope is frozen must still move, we will also discover indications of what freezes scope. It is a result of local calculations of economy applying to movement operations and imposing an order on their application.

\section{Scope Freezing Relativized}

Two pieces of evidence indicate that QR must still be possible even when scope is frozen. The first comes from intensional contexts, where it has been shown that quantifiers in ACD must take widest scope (Sag 1976, Larson and May 1990). In the case of the double object construction, both quantifiers have to take scope over what is interpreted as the antecedent for the ellipsis, indicating that both quantifiers must raise. The second piece of evidence is that scope freezing is only relative, holding only between two object quantifiers, but not between the subject and either of the two objects. This fact clearly indicates that there is nothing about the double object structure or the with variant of the spray-load construction that prevents QR. It also indicates that it is the competition between two quantifiers that results in frozen scope, which points to a Superiority account.

\subsection{Intensional Contexts and ACD}

One of the strongest pieces of evidence, discussed in section 3, for the view that the interpretation of ellipsis in ACD is dependent on QR comes from the correlation between wide scope for 
the quantifier and the possible resolution of ACD. Frozen scope contexts present an apparent counterexample to this correlation. However, on closer inspection the correlation also holds in frozen scope contexts, and in a way that implicates movement of both objects.

Sag (1976) and Larson and May (1990) note that quantifier scope ambiguities with respect to intensional verbs disappear in ACD. Specifically, sentences such as (25b) lack the de dicto reading that is available in (25a).

(25) a. Ozzy wanted every book that Kate wrote.

b. Ozzy wanted every book that Kate did [vp $\Delta]$.

In (25a) every book can take either wide or narrow scope with respect to the intensional verb want. On the narrow scope or de dicto reading, Ozzy, being a fan of Kate, can simply desire any book that she wrote. On the wide scope or de re reading, he desires a certain set of books, perhaps without even knowing that Kate wrote them all. However, the first reading disappears in (25b); it can only mean that Ozzy wants a certain set of books, all of which Kate also happens to want. The QR account of ACD predicts this lack of ambiguity: since the quantifier must move out of the antecedent to resolve ACD, it necessarily takes scope over any intensional verb interpreted as part of the antecedent.

The same thing can be shown to hold in the frozen scope sentences we have been discussing. Consider the following two sentences:

(26) a. I refused to load the truck with every box you told me to dump.

b. I refused to load the truck with every box you told me to [ $\mathrm{vP}$ refuse to load the truck with].

In (26a) every box can be interpreted either de re or de dicto. On the former reading, what I did was refuse to load the truck with a set of boxes, each of which you had told me to dump (perhaps I had forgotten which ones they were). On the latter reading, what I refused to do was to put any boxes that you had commanded me to dump on the truck (perhaps without even knowing which ones they were). The second reading is missing in (26b) if the ellipsis includes refused: every box must take wide scope over refused, such that there were potentially multiple refusals, not a single categorical refusal.

Thus, we see that the correlation between scope and ACD still holds in a strong form. The relevant quantifier must raise out of the antecedent for the ellipsis and take scope over any elements interpreted as part of the antecedent, as the available readings in intensional contexts show.

Moreover, it is not just the second object, the NP that actually hosts the ellipsis, that must take scope over the antecedent. The first object must as well, such that both objects must be interpreted with scope over an intensional verb. ${ }^{11}$

${ }^{11}$ For most speakers fill in examples $(27 \mathrm{a}, \mathrm{c})$ does not alternate, but in its basic use it also shows scope freezing: $I$ filled a (\#different) glass with each drink. 
(27) a. Ozzy refused to fill a glass with every drink that Monty did [vp refused to fill].

b. Reuben wanted to award an athlete every medal Eva did [vp wanted to award].

c. Ozzy refused to fill a glass with every drink.

In (27c) Ozzy can have refused to fill some glass (any glass) with every drink (either at once or sequentially). This is the de dicto reading. Or, he can have refused to fill a certain glass with every drink - the de re reading. (Note that there is no reading in which every drink is interpreted de re while a glass is interpreted de dicto.) In contrast, (27a) does not possess the former reading. It has to be that there was a single glass into which Ozzy refused to put all of the drinks that Monty also refused to put there. ${ }^{12}$ Similarly for (27b).

Frozen scope contexts, then, do not actually constitute a counterexample to the correlation between scope and ACD. Quantifiers in these contexts show the same lack of ambiguity with respect to intensional verbs in ACD as quantifiers in nonfrozen contexts (de dicto readings are lacking). Moreover, scope ambiguity disappears not just for the quantifier hosting the ellipsis, but for both quantifiers in a scope-freezing environment. The conclusion must be that both objects necessarily raise; and since the relative scope between them is fixed, this raising must be unable to reorder the two quantifiers.

\subsection{Scope over the Subject}

The second indication that scope freezing does not mean an inability to raise is the fact that the scope of a second object is not absolutely fixed. Even though the second object cannot take scope over the first object in scope-freezing environments, it can still take scope over the subject. For example, in (28a-b) teachers and judges can vary with books and medals, respectively, while in (28c), which shows that award is subject to scope freezing, athletes cannot vary with medals.

(28) a. A (different) teacher gave me every book.

b. At least two judges awarded me every medal. every $>a$

c. The judges awarded a (\#different) athlete every medal.

every $>$ at least two

*every $>a$

Informants who have initially objected to (28a) readily agree that (28b) has an interpretation where in every athletic event, at least two judges thought that I should have received the medal. ${ }^{13}$ The reading can be made more salient by supplying a context.

\footnotetext{
12 This could involve what Fiengo and May (1994) dub "vehicle change," in which a pronoun is substituted in the ellipsis for an R-expression in the antecedent, such that at LF (27a) is . . Monty did [vP refuse to fill it with $x$ ]. What is important, however, is that such sentences do not have an interpretation in which the universal quantifier (the second object) has wide scope over the existential (the first object).

Such sentences have another meaning as well: one in which there is a different glass for each of the subjects, Ozzy and Monty. It is not clear what the logical form for such an interpretation would be, but note that even here the indefinite a glass is still necessarily interpreted de re.

${ }^{13}$ These judgments have been elicited from over a dozen native speakers; they seem to hold robustly for all geographical regions (including British English and Indian English).
} 
(29) Me and my sister got lots of books from our grade-school teachers. We both have several Judy Blume books, The Wind in the Door, and Bridge to Terabithia. My sister got all of hers from the same teacher, Mr. Roberts. But a different teacher gave me every book. I got The Wind in the Door from Mrs. Wight and Bridge to Terabithia from Miss Benton.

The ability of the second object to take scope over the subject is confirmed by the bound variable test.

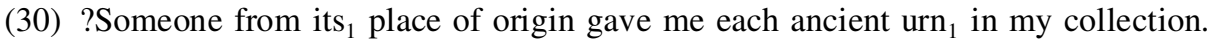

Scope over the subject appears in the with variant of the spray-load alternation as well. In (31a), for example, each color of paint could have been applied by at least two children. The bound variable test makes the same point in $(31 \mathrm{c}-\mathrm{d})$.

(31) a. At least two children smeared that board with each color of paint.

?each $>$ at least two

b. A (different) waiter filled my glass with each drink last night. each $>a$

c. ?Someone familiar with its ${ }_{1}$ properties sprayed Officer Riley with each kind of Mace $_{1}$.

d. ?A waiter from its ${ }_{1}$ place of origin filled my glass with each wine ${ }_{1}$ last night.

Wh-questions make the same point, perhaps more clearly for some speakers, for both the double object construction and the spray-load alternation. The questions in (32) have pair-list readings, while the frozen scope examples in (33) do not.

(32) a. Which judge awarded Eddy the Eagle each trophy? $\quad P-L O K$

b. Which waiter filled your glass with each drink? $\quad P-L O K$

c. It took me forever to find out who provided him with each alibi. $\quad P-L O K$

(33) a. Which athlete did they award each trophy? $* P-L$

b. Which glass did they fill with each drink? $\quad * P-L$

c. It took me forever to find out who they provided with each alibi. $\quad * P-L$

Although the second object in these constructions is prevented from taking scope over the first object if the latter is a quantifier (as we saw in section 2), the second object is able to take scope over the subject. This fact shows that in principle the second object is able to raise. That is, it cannot be the case that the second object in a double object structure is simply prohibited from moving, for whatever reason. It is only with respect to the first object that the second object is frozen (cf. Larson 1990).

In principle, then, QR is available to the second object in scope-freezing environments. There cannot be a structural barrier to movement of the second object. Moreover, the facts of the previous section-intensional verbs in ACD_-showed that even when both objects are quantifiers, QR must be available. Descriptively, then, scope freezing refers only to the relation that obtains 
between two object quantifiers. Both are free to take scope with respect to other operators, ${ }^{14}$ and both can take scope over the subject.

The next section proposes that the facts of scope freezing are exactly analogous to what we see in cases of Superiority in wh-movement. The Superiority Condition (Chomsky 1973) was proposed to account for a preference for extracting the structurally higher one when two or more elements are eligible for the same movement. In the case of multiple $w h$-movement, all whphrases move to the same target position, Comp or [Spec, CP]. But the highest one is constrained to move there first.

(34) a. Which armchair did you drape $t$ with what?

b. *Which sheet did you drape what with $t$ ?

This looks much like the cases under consideration, where a lower quantifier cannot move without a higher one moving first. In English wh-questions it is not obvious that the second wh-phrase moves to a position below and c-commanded by the first. Languages with multiple wh-fronting, however, show this clearly (as laid out in the next section), making the analogy complete: in multiple instances of movement, including $\mathrm{QR}$, the higher item must move first and continue to take scope over the lower.

(35) Maud $\mathrm{Q}_{1} \mathrm{Q}_{2}$ draped [an armchair] with [every sheet].

Objects will be shown to differ from subjects, however, in that subjects move for reasons other than scope (the Extended Projection Principle (EPP)), which permits them to reconstruct. No reconstruction is possible for objects, resulting in scope ambiguities between objects and subjects but frozen scope between multiple objects in specific configurations.

\section{Ordering Constraints on Movement}

The fact that QR is unable to change the relative scope of two objects is strikingly reminiscent of cases of multiple wh-movement in languages like Bulgarian. In such languages the moving wh-words cross paths, recreating after movement the hierarchical order that obtained between them prior to movement (Rudin 1988, Bošković 1995, Richards 1997). This crossing of paths has been argued to follow from Superiority (Richards 1997), viewed as an economy condition on movement. This section illustrates recent findings in this domain, and the Superiority-based account of them, and further argues that QR behaves in the same fashion. Just as Superiority - formalized following Richards as Shortest, a combination of Shortest Attract and Shortest Move-forces crossing paths in wh-movement, I argue that it forces crossing paths in the case of QR as well.

${ }^{14}$ Kyle Johnson (personal communication) points out that the second object can also take scope over negation, as in She didn't show me many of the answers. 


\subsection{Crossing Paths}

Work on multiple $w h$-questions, among other phenomena, has discovered that multiple movements of the same type cross paths, preserving the original hierarchical order of the moved elements. For instance, multiple questions in a multiple $w h$-fronting language like Bulgarian recreate their original order at the left periphery, as shown in (36).

(36) Bulgarian (Rudin 1988:449)

a. Koj kogo vižda?

who whom sees

'Who sees whom?'

b. *Kogo koj vižda?

c. $\quad$ koj kogo $t_{\text {subj }}$ vižda $t_{\text {obj }}$

Richards (1997) argues that movement of this sort targets the same position, [Spec, CP] in the case of $w h$-movement. If this is correct, it contradicts the view that multiple instances of movement to the same position adjoin to successively higher projections. Instead, instances of movement beyond the first apparently "tuck in" beneath the first moved element, resulting in the phenomenon of crossing paths.

The empirical evidence that multiple movements to the same position regularly behave in this manner comes from a variety of sources, not just multiple $w h$-movement. Richards cites several phenomena in support of this generalization, among them multiple $w h$-movement in languages from Bulgarian to Tibetan, scrambling of idiom chunks in Japanese, scrambling in general, object shift of multiple objects (which will be discussed briefly below), and clitic clustering (modulo interactions with the morphology). As a further illustration, one of these will be reviewed here: scrambling of idiom chunks in Japanese.

Richards notes first that idiom chunks are restricted to local A-scrambling in Japanese (as observed by Miyagawa (1997)). Second, this local scrambling is subject to Superiority: if only one idiom chunk scrambles, it must be the highest.

(37) Japanese (Richards 1997, (34))

a. Taroo-ga hi-ni abura-o sosoida.

Taroo-NOM fire-DAT oil-ACC poured

'Taroo made things worse.'

b. Hi-ni, Taroo-ga $t_{1}$ abura-o sosoida.

c. * Abura-o ${ }_{1}$ Taroo-ga hi-ni $t_{1}$ sosoida.

If both idiom chunks scramble, their original order is preserved. If short A-scrambling targets a single position, these facts form part of the same generalization as the Bulgarian data: multiple instances of movement cross paths. 
(38) Japanese (Richards 1997, (35))

a. Hi-ni ${ }_{1}$ abura- $\mathrm{O}_{2}$ Taroo-ga $t_{1} t_{2}$ sosoida.

fire-DAT oil-ACC Taroo-NOM poured

'Taroo made things worse.'

b. *Abura-o 2 hi-ni ${ }_{1}$ Taroo-ga sosoida.

c. hi-ni ${ }_{1}$ abura-o $\mathrm{O}_{2}$ Taroo-ga $t_{1} t_{2}$ sosoida

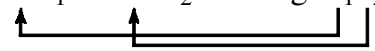

Given the mass of evidence accumulated by Richards indicating that multiple elements moving to the same position behave this way, it is reasonable to pursue the idea that frozen scope is an instance of the same phenomenon. They are tantalizingly similar: we have seen that the two quantifiers inside the VP in frozen scope contexts must move, or at least are able to move, yet this movement does not create a new scope relation between the two quantifiers. The obvious step to take is to recognize that crossing paths are forced in the case of QR as well. Because crossing paths are a result of the same economy principles that derive the Superiority Condition (as shown in the next section), QR is therefore subject to Superiority.

\subsection{Superiority as Economy}

Much recent work (Chomsky 1993, Kitahara 1994, 1995, 1997, Richards 1997) has argued that the Superiority Condition is derived from a more general principle of economy, Shortest Attract or Shortest Move (cf. the Minimal Link Condition of Chomsky 1995:311), which underlies an entire class of constraints on movement (such as Relativized Minimality effects). On the view that movement is driven by featural attraction to a head (39), such that the attracted element must enter into a checking relation with the head by moving to a specifier of that head (Chomsky 1993), Shortest Attract ensures that the highest available element will be attracted prior to any lower one. Attract must target the closest available element of the correct featural type. This will account for Superiority effects in English, where only one wh-phrase moves overtly, and this element must be the highest one. Richards (1997) goes further, arguing that crossing of paths falls out from the same constraint as well, once it is understood as a more general economy principle that subsumes both Shortest Attract and Shortest Move. This condition is stated as Shortest (Richards 1997:113).

(39) Attract

An attractor $\mathrm{K}$ attracts a feature $\mathrm{F}$, creating a copy $\alpha^{\prime}$ of an element $\alpha$ containing $\mathrm{F}$, and merging $\alpha^{\prime}$ with $\mathrm{K}$. The relations between $\alpha^{\prime}, \mathrm{K}$, and $\mathrm{F}$ must all obey Shortest.

(40) Shortest

A pair $\mathrm{P}$ of elements $[\alpha, \beta]$ obeys Shortest iff there is no well-formed pair $\mathrm{P}^{\prime}$ which can be created by substituting $\gamma$ for either $\alpha$ or $\beta$, and the set of nodes c-commanded by one element of $\mathrm{P}^{\prime}$ and dominating the other is smaller than the set of nodes c-commanded by one element of $\mathrm{P}$ and dominating the other. 
Shortest constrains both which element the head attracts (Shortest Attract) and how far that element moves (Shortest Move). Consider the case where a head K can potentially enter into a checking relation with two elements $\alpha$ and $\beta$, shown in (41a).
a. $[K[\ldots \alpha[\ldots \beta]]]$
b. $\left[\mathrm{KP} \underset{\alpha^{\prime}}{\alpha}[\mathrm{K}[\ldots \alpha[\ldots \beta]]]\right]$
c. $\left.\left[{ }_{\mathrm{KP}} \alpha^{\prime}{ }_{\mathrm{KP}} \beta^{\prime}[\mathrm{K}[\ldots \alpha[\ldots \beta]]]\right]\right]$

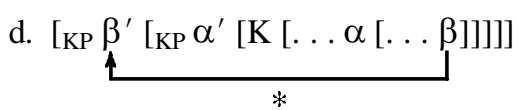

In such a case Shortest forces $\alpha$ to move first rather than $\beta$ (41b), since the set of nodes c-commanded by $\mathrm{K}$ and dominating $\alpha$ is smaller than the set dominating $\beta$ (this is the Superiority Condition, now viewed as Shortest Attract). When $\alpha$ moves, the shortest movement it can perform is to the specifier of $\mathrm{K}(41 \mathrm{~b})$. Once $\alpha$ has moved, if it is still possible (or necessary) for $\beta$ to move, it is free to do so, as there is no longer a well-formed pair of elements $\mathrm{P}^{\prime}$ in contrast to the pair $\mathrm{P}$ formed by $\mathrm{K}$ and $\beta$. Shortest now constrains the movement of $\beta$ as well, by constraining the relation between $\beta^{\prime}$ and $\beta$ (Richards 1997:280): $\beta$ must move and merge into a new specifier as close as possible to the head $\mathrm{K}$ (rendering the distance between $\beta^{\prime}$ and $\beta$ as short as possible), which means tucking-in, as shown in (41c). The movement in (41d) is ruled out by the existence of the well-formed pair $\left\{\beta^{\prime}, \beta\right\}$ of (41c). Shortest thus holds of the chain formed by movement as well as the relation between attractor and attractee. In this manner crossing paths are forced by Shortest Move, a subcase of Shortest. ${ }^{15}$

Note that this account requires extremely local computations of economy, of the sort proposed by Collins (1997). On a global approach to economy, entire derivations are compared, and those that involve less economical operations are ruled out. In the case of multiple instances of movement to the same position, it is not clear how Shortest could have the effects it is intended to if economy is calculated globally. Consider the examples of multiple $w h$-movement that Richards discusses. It is not the case that Shortest prevents a particular movement from occurring; it simply imposes an ordering among movements. On a global view of economy there might ultimately be no advantage in attracting the higher $w h$-phrase first, given that the higher and the lower $w h$-phrases both end up moving (and that Attract is not exhausted after one application). On a strictly local view of economy, however, where economy is computed derivationally and with respect to operations, the facts of multiple wh-movement fall into place. At the point of potentially applying an operation (Move), Shortest will constrain that operation to be as local as possible, with no regard to future operations. Thus, when a $[+$ wh $] \mathrm{C}$ must attract a wh-phrase, Shortest evaluates at that

${ }^{15}$ See Richards 1997 for discussion of cyclicity concerns that arise in such instances of movement. Briefly, cyclicity is an epiphenomeno $n$ arising from the need for immediate satisfaction of featural requirements, and by the fact that most features are checked by only one instance of movement. It is exactly the cases of multiple movement that show that there really is no cyclicity and no Extension Condition (Chomsky 1995). See also Collins 1997. 
point only which relation is the most local, and which operation of Move the shortest. It makes no difference whether another $w h$-phrase will be attracted.

The same considerations will apply in the case of QR. While violating Shortest might result in a different semantics (and might hence be expected to permissibly violate economy conditions, as in Fox 1995b), and might even globally be more economical than obeying Shortest, it must be the case that the syntax is blind to such considerations and only cares about calculations of syntactic economy at each point in the derivation. Exactly how this works in the case of QR is explored in the next section.

\subsection{QR Obeys Shortest}

The constraint on movement operations that ensures that higher elements must move before lower ones applies straightforwardly in the case of $w h$-movement and other instances of movement that are plausibly driven by featural attraction. It is not immediately apparent how Shortest will apply to $\mathrm{QR}$, an operation that is not obviously driven by uninterpretable features in the sense of Chomsky (1993), or by a generalized version of the Wh- and Neg Criteria of Rizzi (1990), Haegeman and Zanuttini (1991), Sportiche (1996). In such cases an identifiable head (C, Neg, or a hypothesized Clitic head) bears a feature that attracts elements of the appropriate type: $w h$ words, negative phrases, or certain types of noun phrases. QR arguably makes use of positions that are already available_-VP, TP, DP, for instance — and, as seen in ACD, seems to be able to move quantifiers to successively higher positions (or at least to different positions). It is not clear that there could be a [quantifier] feature, unless that feature could optionally be present on a variety of different heads in any given clause.

The empirical evidence also indicates that $\mathrm{QR}$ is an operation that is driven by interpretation, as proposed specifically within recent syntactic theory by Fox (1995b) and Kennedy (1997) (see section 7 for more discussion of the nature of QR). Does this mean that it should fall outside the purview of syntactic constraints like Shortest? What follows is a speculative way of understanding the driving force behind $\mathrm{QR}$ as a type of feature movement while still capturing the idea that $\mathrm{QR}$ is driven by semantic considerations. It is not the only conceivable approach, but it does hold some promise. ${ }^{16}$ This is to think of QR as an operation of chiefly semantic import that nevertheless is syntactic in mechanism, meaning that it operates in the same fashion as other types of movement: by Attract (of a syntactic feature). This will enable a relatively straightforward application of Shortest to quantifier movement. The semantics will enter into the derivation by interpreting the output of the syntactic mechanism.

This conception of quantifier movement is based on proposals by Chomsky (to appear) regarding object shift of the type found in Germanic languages. Chomsky observes that object

${ }^{16}$ Applying Shortest to movement that is not driven by features is also possible, which would also capture the intuitions about QR expressed here. One method would be to adapt Collins's (1997) Minimality principle to apply to operations of all kinds, including interpretive movements like QR. In this case Shortest would force the shortest possible instance of any operation of QR when that operation becomes available. The only difference between this approach and the one outlined in the text would be the driving force behind the movement. 
shift has an interpretive effect in the languages in which it applies (being tied to the semantics of specificity), but argues that it is nonetheless not driven by an interpretive condition. Instead, it is a purely formal movement identical in operation to A-movement of the subject to TP, for example, or $\bar{A}$-movement of $w h$-phrases to a $[+$ wh] CP. It so happens that the interface with the semantics makes use of the syntactic difference between applying the operation or not, but the semantics is not what drives the movement.

In the specific case of object shift, Chomsky hypothesizes a feature that can optionally be present on the light verb $\mathrm{v}$ (the head that projects the external argument and selects the verb phrase as its complement; see below), which will attract the object under feature matching. This attraction results in object shift. If this feature, which Chomsky calls a P-feature, is not present on $\mathrm{v}$, object shift will not occur, by economy principles that require a motivation for any movement. The semantics makes use of the difference between a v with a P-feature and one without, even resulting in semantically deviant structures if the movement wrongly does or does not apply, but it is not the semantics itself that forces object shift. It is the purely formal presence of a P-feature that requires matching that drives movement. ${ }^{17}$

Suppose that something like this is correct: that the syntax has a limited number of resources available to perform operations, which must be made use of in deriving different semantic interpretations. Suppose further that movement can only take place under feature matching, of the sort just described. Then $\mathrm{QR}$, like object shift, must involve purely optional features to result in the correct interpretation. A head of the appropriate type can be selected with a P-feature, which will force QR; if the head does not have the feature, a quantifier will be unable to raise and the derivation will result in a different interpretation, possibly a deviant one.

Suppose further that heads that can appear with P-features are parameterized across languages in which features they match and consequently attract, according to semantic interpretation. In the languages with object shift, the semantic notion that makes use of P-features is specificity. Given that specificity is not an inherent part of a DP, and that almost any DP can be given a specific interpretation, $v$ will simply match $\phi$-features of DPs and attract them, by virtue of the P-feature. Any DP object will be eligible for movement to v. If more than one is available, $v$ can attract both to multiple specifiers. In this case, as in the case of QR, it will only be able to do so in a certain order, obeying Shortest. This accounts immediately for the observation from object shift languages that the shifting of multiple objects acts just like A-scrambling of idiom chunks in Japanese: if only one object shifts, it must be the higher one (the indirect object); and if both shift, they retain their hierarchical order. It is not possible to shift the lower object to the exclusion of the higher.

\footnotetext{
${ }^{17}$ Chomsky's analysis is actually slightly different from this. There is a nonmovement relation that is established between heads and arguments (by feature matching), called Agree, which is a prerequisite for movement. This relation is established in any transitive clause, including ones where object shift does not take place. The function of the P-feature is to make a specifier available for movement, by forcing something that Agrees with the head to appear in the specifier position in order to check the P-feature. P-features are then a generalized form of the EPP: simply a requirement that a specifier be filled.
} 
(42) Icelandic (Collins and Thráinsson 1996)

a. Ég lána ekki Maríu bækurnar.

I lend not Maria the books

'I do not lend Maria the books.'

b. Ég lána Maríu ekki $t_{\mathrm{IO}}$ bækurnar.

c. ?Ég lána Maríu bækurnar ekki $t_{\mathrm{IO}} t_{\mathrm{DO}}$.

d. *Ég lána bækurnar ekki Maríu $t_{\mathrm{DO}}$.

These facts have been reported for West Flemish (Haegeman 1993, 1996), Mainland Scandinavian (Falk 1990, Collins and Thráinsson 1996), Dutch and German (Den Dikken and Mulder 1991, Neeleman 1994), and other object shift languages, including Chinese (Soh 1998).

In the case of object shift, then, a specific interpretation will arise whenever $\mathrm{v}$ is chosen with a P-feature. Note, however, that try as one might to shift the direct object to the exclusion of the indirect object, it is simply impossible. This fact is captured by the optional feature approach, lending it some empirical weight, but not by an interpretive condition. If $\mathrm{v}$ is generated with a P-feature, it will necessarily attract the indirect object before the direct object, owing to Shortest. If the semantics were the only factor, forcing specific objects to move, for instance, nothing would rule out the derivation in $(42 \mathrm{~d})$.

In a language like English, where object shift does not apply but QR does, the semantics of the P-feature is tied to the status of a given DP as a quantifier. Unlike specificity, quantificational status is an inherent property of the DP. If heads that can appear with P-features are parameterized according to the interpretation that arises from the presence of the feature, $v$ will not attract DPs that are not of the right semantic type ( $v$ is a probe looking for a quantificational goal, in Chomsky's (2000, to appear) terminology). $\mathrm{v}$ will then only attract quantifiers, accounting for the relative nature of scope freezing. A quantifier will be able to cross over another NP that is not a quantifier, since nonquantifiers will not be attracted to $\mathrm{v}$. If both objects in the double object construction are quantifiers, however, both will be attracted to $\mathrm{v}$, and their movement will be constrained by Shortest to cross paths, just as in overt multiple object shift. This will provide a principled account of frozen scope.

\subsection{Movement to $v$}

Following widely accepted theories of generalized quantifiers (Barwise and Cooper 1981, Heim and Kratzer 1998), I will assume that object quantifiers are uninterpretable in situ and must raise to a node that denotes a closed proposition (a node of type $\langle t\rangle$ ). This requirement follows from the generally assumed conditions on the interpretation of quantifiers: they must bind a variable (the constraint against vacuous quantification), and they must combine with an open formula created by abstracting over a closed proposition (see also the discussion of quantification in the 
Minimalist Program in Kennedy 1997). There are a variety of positions of the appropriate type to which quantifiers can move, the first available one being the maximal projection of the head that projects the external argument. Following recent theories of VP phrase structure, the external argument is introduced by a verbal head above the lexical verb, called $v$ (Chomsky 1995, Marantz 1997; cf. Kratzer's (1996) Voice head and Collins's (1997) Transitivity head). ${ }^{18}$

(43)

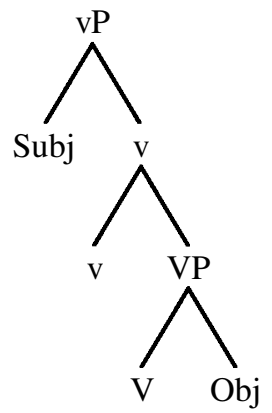

vP is thus the first position of the type appropriate for the interpretation of quantifiers. Before merger of the subject, the proposition denoted by the VP is open and does not constitute a node of the appropriate type. After merger of the subject, $\mathrm{vP}$ is a closed proposition, the predicate having combined with all of its arguments (assuming that Tense and other operators do not matter for the interpretation of quantifiers). There are higher positions of the correct type as well, as there must be in order for an object to take scope over a higher intensional verb, for example. For the moment, however, I will consider only vP; the discussion will generalize to other positions as well, assuming that the P-feature can optionally be present on various heads of the appropriate type.

Suppose with Chomsky that v can optionally appear with a P-feature, a feature that requires an element of the appropriate type to fill its specifier (a generalized version of the EPP in Chomsky 2000 , to appear). In accord with the parameterized version of P-features outlined above, elements of the appropriate type in English are quantifiers. If the VP contains a quantifier, and $\mathrm{v}$ appears with a P-feature, the quantifier will be drawn to the specifier of $\mathrm{v}$. This will permit a convergent interpretation, since the quantifier will be interpretable in this position.

$$
\left[{ }_{\mathrm{vP}} \mathrm{Q}\left[{ }_{\mathrm{vP}} \operatorname{Subj}\left[{ }_{\mathrm{v}} \mathrm{v}^{[P]}\left[{ }_{\mathrm{VP}} \mathrm{V} t_{\mathrm{Q}}\right]\right]\right]\right]
$$

If $\mathrm{v}$ does not have a P-feature, the derivation either will be uninterpretable at the interface with the semantics or will require a different interpretation of the quantifier. ${ }^{19}$

${ }^{18}$ Note that this analysis is compatible with the idea that objects move (either overtly or covertly) for Case reasons. According to some such analyses (e.g., Johnson 1991), the position of an object shifted for Case is below the base position of the subject, which would mean that even a moved quantificational object is uninterpretable without QR to move it further (past the position of the subject). Given appropriate constraints on Case-driven object movement, nothing in what follows would be affected. Case-driven movement above the subject could also be made compatible with the present account, provided QR raised quantifier objects even further (permitting Condition $\mathrm{C}$ violations, ACD resolution, etc.); see footnotes 25 and 27.

${ }^{19}$ If indefinites are ambiguous between an interpretation as a generalized quantifier and an interpretation as a choice function (Kratzer 1998, Reinhart 1997), the difference might correlate with the presence or absence of the P-feature. 
The P-feature must be able to attract more than one element of the right type, just as in object shift. In the case of multiple quantifiers inside the VP_-including quantifiers within PPs, whether arguments or modifiers - the P-feature of $\mathrm{v}$ will permit all of them to move.

As Barss and Lasnik (1986), Larson (1988), and Pesetsky (1995) have shown, in double object and spray-load configurations the first object asymmetrically c-commands the second (see section 6 for the structure of the complex-predicate construction that is adopted here, and the difference between this and the locative variants). By Shortest, $v$ must attract the higher quantifier first if both objects are quantifiers. Once this has happened, the second quantifier is attracted as well.

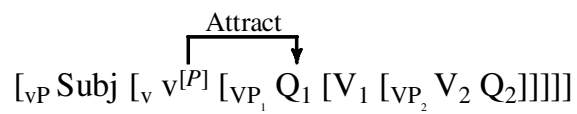

At the point shown in (45), $\mathrm{v}$ has a P-feature that permits movement of quantifiers (by Attract) to the specifier of $v$. According to Shortest, $\mathrm{Q}_{2}$ may not be attracted in this configuration, because a well-formed pair exists $\left(\left\{\mathrm{v}, \mathrm{Q}_{1}\right\}\right)$ that is smaller than the pair $\left\{\mathrm{v}, \mathrm{Q}_{2}\right\}$. Because attracting $\mathrm{Q}_{2}$ does not, at this point, obey Shortest, nothing can force the movement of $\mathrm{Q}_{2}$ prior to $\mathrm{Q}_{1}$. In particular, Shortest cannot be overruled even if moving $\mathrm{Q}_{2}$ first would produce a different interpretation. $\mathrm{Q}_{2}$ can and in fact must raise, but this is permitted by Shortest only after the shorter movement of $\mathrm{Q}_{1}$ has taken place.

After the movement of $\mathrm{Q}_{1}, \mathrm{Q}_{2}$ will be drawn to $\mathrm{v}$ as well, checking features in the same way as multiple wh-movement, for example, or movement of two objects in object shift. The Pfeature of $\mathrm{v}$ will be satisfied, while the semantic requirement that quantifiers raise to an interpretable position will have also been met. When $\mathrm{Q}_{2}$ does raise, it will tuck in beneath $\mathrm{Q}_{1}$, as dictated by Shortest and illustrated above for Bulgarian multiple questions, Japanese scrambling of idiom chunks, and Icelandic double object shift. This derivation is illustrated in (46). ${ }^{20}$ The result is the inability of QR to change scope relations, by purely formal restrictions on the way that syntactic movement works. As much as the semantics might like to reverse the order of the two VP-internal quantifiers $Q_{1}$ and $Q_{2}$, doing so is ruled out by the same constraints that derive the Superiority Condition and intervention effects generally. As stated above, this impotence follows from the view that semantic interpretation is not itself a driving force in syntax, but merely interprets the output of purely syntactic mechanisms. ${ }^{21}$

${ }^{20}$ Note that $\mathrm{Q}_{2}$ is unable to make the shortest conceivable movement and tuck in beneath the subject. This would follow if specifiers made available by P-features are outside of a thematic specifier, as hypothesized by Chomsky (2000, to appear). The quantifier would also be uninterpretable beneath the subject, a consideration that might also render such a derivation ill formed.

${ }^{21}$ The Scope Economy principle of Fox (1995b) might be stated in this theory in the following way: a head may only appear with a P-feature if that head is an operator (e.g., an intensional verb) or contains, within its specifier, another quantifier. The result will be that no lower quantifier will be able to raise unless raising changes scope relations. This idea has the virtue of making economy immediately determinable, avoiding problems of look-ahead inherent in other implementations. 
(46)

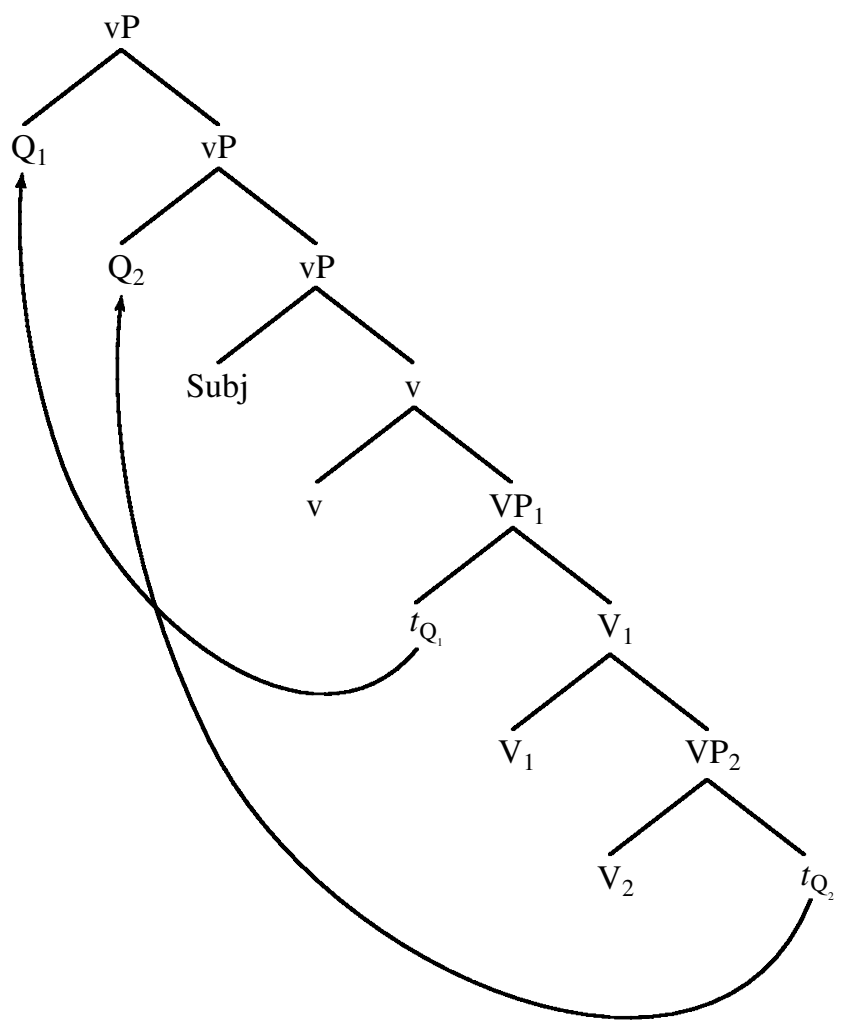

Although scope relations are unable to change, the fact that QR nevertheless takes place permits a ready explanation of the ACD facts.

\subsection{Scope Freezing and ACD Explained}

A simple case of frozen scope and ACD is shown in (47). Both objects are quantifiers, the second one including a relative clause with an elided VP. Both must move owing to the optional Pfeature of $\mathrm{v}$, but the first object must move prior to the second, by Shortest, given that it is hierarchically higher than the second. After the first object has moved, the second is permitted to move, tucking in beneath the first.

(47) Ozzy gave someone everything that you did [ $\left.{ }_{\mathrm{vP}} \Delta\right]$.

(48) $\left[\mathrm{vP}_{\mathrm{vP}}\right.$ someone [ ${ }_{\mathrm{vP}}\left[\right.$ everything you did] ${ }_{\mathrm{vP}} t_{\mathrm{Ozzy}}\left[\mathrm{vv}_{\mathrm{v}}\right.$ gave $\left.\left.\left.\left[\mathrm{vP}_{1} t_{\mathrm{Q}_{1}}\left[\mathrm{vP}_{2} t_{\mathrm{Q}_{2}}\right]\right]\right]\right]\right]$

$$
\uparrow
$$

The fact that all quantifiers within the VP must move to vP (to check the P-feature of v) makes satisfaction of the conditions on the interpretation of ACD a trivial matter. As shown in (48), both quantifiers necessarily move to $\mathrm{vP}$, leaving a $\mathrm{VP}$ of suitable form (gave $x y$ ) to serve as antecedent for the ellipsis. These movements are forced to cross paths, as shown. If scope is 
read off the heads of chains exclusively, QR applying to the two objects in such cases will never be able to change their relative scope. But it will permit the resolution of ACD.

Moreover, if, as the movement account of ACD states, a quantifier must necessarily take scope over the antecedent for the ellipsis, the facts of scope in intensional contexts are explained, in the following manner. A head higher than the initial $\mathrm{v}$ can also optionally appear with a Pfeature, permitting each quantifier to move a second time. ${ }^{22}$ Both quantifiers will then be forced to move in a step subsequent to the one shown in (48) to a position above the intensional verb that is interpreted as part of the ellipsis. This second step of movement, of course, will also obey Shortest, and again the quantifiers will be forced to cross paths. Subsequent instances of movement consequently leave scope frozen as well. ${ }^{23}$ The actual requirement imposed by ACD in the examples under consideration is that the second quantifier take scope over the ellipsis. But because of Shortest, and the way attraction by a P-feature works, the only licit derivation in which the second quantifier raises is one in which both quantifiers do. The lower quantifier can never move unless the higher one moves first, since there will always be a well-formed pair consisting of the higher quantifier and $\mathrm{v}\left(\left\{\mathrm{v}, \mathrm{Q}_{1}\right\}\right)$ that is smaller than the pair $\left\{\mathrm{v}, \mathrm{Q}_{2}\right\}$.

To illustrate such further instances of movement, consider (27b), repeated here as (49). The structure after successive-cyclic QR has applied is shown in (50) (ignoring the starting position of the subject and irrelevant details). ${ }^{24}$

(49) Reuben wanted to award an athlete every medal Eva did [vp $\Delta]$. *every $>a$

(50) $\left[{ }_{\mathrm{vP}}\right.$ an athlete ${ }_{1}\left[{ }_{\mathrm{vP}}[\text { every medal Eva did }]_{2}\left[\mathrm{v}\right.\right.$ wanted to [ ${ }_{\mathrm{vP}} t_{1}\left[{ }_{\mathrm{vP}} t_{2}\right.$ award $\left.\left.\left.\left.t_{1} t_{2}\right]\right]\right]\right]$

Subsequent to the two applications of QR (raising both objects), the VP wanted to award $t_{1} t_{2}$ is of suitable form to serve as antecedent for the ellipsis. Since both objects have moved to a position above wanted, they both must take scope over that verb. In moving, their relative scope never changes, because of Shortest. Thus, the correlation between scope and ACD still holds: if wanted is interpreted as part of the ellipsis, both quantifiers must take scope over it.

\subsection{Scope over the Subject}

The scope relation holding between two VP-internal quantifiers is thus an instance of the more general phenomenon of crossing paths, forced by Shortest whenever two or more elements move to the same position (Richards's generalization for multiple instances of movement). Recognizing the conditions in which Shortest comes into play also explains the other piece of evidence that QR is still available in frozen scope environments, namely, the fact that the second object is able to take scope over the subject even though it cannot take scope over the first object.

Before it can be shown how a second object can take scope over a subject, the movement

${ }^{22}$ It is also conceivable that only this higher head might have a P-feature, resulting in a single step of movement.

${ }^{23}$ Note that there must be a strict hierarchical order among multiple specifiers for Superiority to hold of further movement (there is no Equidistance). That this must be the case is evident from the fact that successive-cyclic movement generally evidences Superiority (*What do you think who bought?).

${ }^{24}$ I have labeled the complement of want "vP," although it could be a TP as well. See Wurmbrand 1998 for discussion. 
that permits a single object to take scope over a subject must be explained. Cases of Superiority in $w h$-movement display an asymmetry between subjects and objects, such that an object is never able to move prior to a subject (*What did who see?). One might expect the same to hold in QR: since the subject is always structurally higher than the object, QR should be unable to change their relative scope. But transitive sentences such as A girl kissed every bride are ambiguous in English.

The ability of an object to take scope over a subject can be explained by a crucial difference between wh-movement and QR. Wh-movement moves elements within a clause to a higher position, namely, [Spec, CP]. Both subjects and objects must move in order to satisfy the requirements of $w h$-questions (a requirement of C). Shortest therefore forces the highest one to move first and the second one to tuck in beneath it, as can be seen overtly in languages like Bulgarian. The parallel situation does not arise in all cases of QR, however. Subjects do not need to move by any semantic consideration, since they are already in a position in which they can be interpreted: either their base position at vP or their derived position at TP (e.g., Heim and Kratzer 1998). Moreover, if the semantics makes use of the optional mechanism of P-features on $\mathrm{v}$ and other relevant heads (such as T) to raise quantifiers, as hypothesized here, raising will simply never apply to the subject, since it is already at $\mathrm{v}$ (in the same way as object shift never moves a subject). Because subjects are ineligible for P-feature movement (they are not in the search space of $v$, its domain; Chomsky 1993), subjects and objects do not compete for movement to the same position. Because there is no competition, Shortest does not come into play at all. That is, at the point of moving an object quantifier to $\mathrm{v}$, there will be no well-formed pair that is shorter than the pair $\{\mathrm{v}, \mathrm{Obj}\}$; hence, nothing will prevent movement of the object quantifier to a specifier above the base position of the subject.

The subject itself undergoes overt movement to [Spec, TP], for unrelated reasons (the EPPfeature of $\mathrm{T}$ according to Chomsky 2000). If this movement is permitted to reconstruct, placing a quantified subject back in its base position as far as scope is concerned (e.g., May 1977, Johnson and Tomioka 1997), inverse scope will be derived by the same movement necessary for the interpretation of an object quantifier independent of the presence of a quantificational subject. If the subject does not reconstruct, surface scope will result.

Since there is only one possible operation of movement to $v$ to consider, Shortest will be trivially satisfied. This is illustrated for (51a) in (51b).

(51) a. A girl kissed every bride.

every $>a$
QR
b. $\left[{ }_{\mathrm{TP}} \mathrm{a} \underset{\mathrm{girl}}{\mathrm{S}}\left[\mathrm{T} \mathrm{T}\left[\mathrm{vP}\right.\right.\right.$ every bride ${ }_{\mathrm{Q}}\left[{ }_{\mathrm{vP}} t_{\mathrm{S}}\left[\right.\right.$ kissed $\left.\left.\left.\left.\left.t_{\mathrm{Q}}\right]\right]\right]\right]\right]$

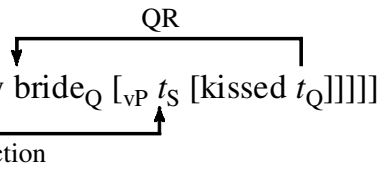

After the subject $a$ girl has moved to TP to satisfy the EPP, it is permitted to reconstruct to its base position, taking scope under the raised object. ${ }^{25}$

Reconstruction is available for the subject but not for objects moved covertly, as is evident

${ }^{25}$ It may be that reconstruction of the subject takes place to an intermediate position rather than to its base position 
from the fact that crossing paths result in unambiguous scope. It appears to be the case that only non-scope-taking movement can reconstruct, a restriction that plausibly follows from the Scope Economy principle of Fox 1995b. By Economy, it is better to simply not apply QR than it is to raise a quantifier and then lower it again.

It is part of the definition of Superiority that its effects are found only between two elements that are both eligible for the same movement operation. They will never be found between one element that does not undergo an operation (and is furthermore ineligible for it) and another that does. Because the subject cannot be attracted by the P-feature of $v$, it will not interact with object quantifiers in a way that respects Shortest. ${ }^{26}$

Returning to scope-freezing environments, we saw that even though the second object could not take scope over the first object, it could still take scope over the subject. This fact will follow in the same way as the ability of a single object to take wide scope. Consider (28a), repeated here.

(52) a. A (different) teacher gave me every book. every $>a$

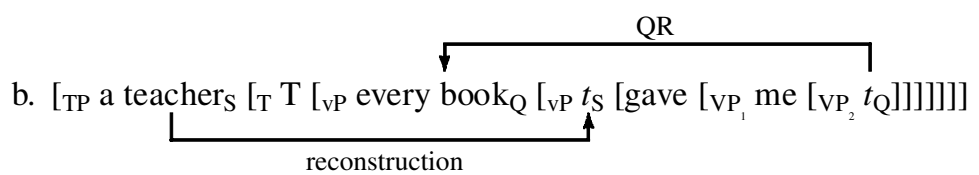

Scope is free in such a case just as it is in the simple case of a subject and object quantifier (with no other arguments present; see (51)). There is only one operation of raising to consider, that of moving every book, since $m e$ is not eligible for attraction to $\mathrm{v}$ by the relativized P-feature. Because only one element is eligible for movement, Shortest applies vacuously and the second object is free to raise first to $\mathrm{vP}$, taking scope over the subject if the latter reconstructs. ${ }^{27}$

\subsection{Prediction: Passives}

One prediction of the current proposal is that subjects generally will participate in scope ambiguities, while two objects will not. As shown above, this is due to the fact that subjects are ineligible for attraction by P-features. The same should hold of derived subjects as well.

(Johnson and Tomioka 1997), which would require further QR of the object to some higher head. This higher head would also have to be able to have a P-feature, by hypothesis. This alternative may be necessary given the facts of multiple quantifiers; see footnote 27.

${ }^{26}$ It should be noted that these statements apply to English and languages like it, which permit scope readings other than those given by the surface order of quantifiers. Something else constrains scope in languages that allow only surface scope (P-features might be parameterized differently, as in object shift languages), but the hypothesis advanced here should make its effects felt even in such languages.

${ }^{27}$ One obvious question to ask is what happens when the subject and both objects are all quantifiers. The judgments are extremely difficult and unstable, but the answer seems to be that, as would be expected, both quantifiers can together take scope over the subject, provided that their own relative scope does not change. However, it is much easier for only the first object to take scope over the subject than it is for both objects to simultaneously take scope, a fact unexpected on the simple reconstruction story told in the text. The facts would make sense if, as suggested in footnote 25 , the inverse scope reading required further movement of object quantifiers to a higher position (possibly even to TP), plus reconstruction of the subject. If $\mathrm{vP}$ is the only relevant position, one would expect inverse scope to require both objects to take scope together over the subject, contrary to fact. 
As we saw, scope is frozen in the double object construction, such that only the surface scope reading is available (53a). Now consider (53b), the same sentence except that it has been passivized.

(53) a. Ozzy gave a (\#different) girl every telescope. *every $>a$ b. A (different) girl was given every telescope. every $>a$

Suddenly inverse scope is available, and girls can vary with the telescopes that were given.

On the simplistic view that QR cannot raise the second object of a double object verb, (53b) is a mystery. On the theory outlined here, it is expected. The first object moves to [Spec, TP] for reasons other than QR (the EPP), just as the subject of an active sentence does. It is then permitted to reconstruct to an intermediate position, by the considerations outlined above (and in footnotes 25 and 27). When the second object raises, there is no competitor eligible for QR, permitting the movement in conformity with Shortest. The quantifier can take scope over the subject of a passive in the same manner as the subject of an active, by reconstruction. ${ }^{28}$

The same holds for the spray-load verbs we have been considering.

(54) a. Ozzy draped a (\#different) armchair with each sheet.

$* e a c h>a$

b. A (different) armchair was draped with each sheet.

each $>a$

Note that such passives behave exactly like their locative counterparts, as expected.

(55) a. Ozzy gave a (different) telescope to each girl.

each $>a$

b. A (different) telescope was given to each girl.

each $>a$

(56) a. Ozzy draped a (different) sheet over each armchair.

each $>a$

b. A (different) sheet was draped over each armchair.

each $>a$

Because it limits scope possibilities by Superiority (Shortest) — that is, by competition between elements undergoing the same movement-the theory developed here provides a natural account of the sudden ambiguity in passivized double object and spray-load constructions. Other theories do not fare so well (e.g., Aoun and Li 1993). ${ }^{29}$

\subsection{Summary}

This section has shown that multiple instances of movement to the same position do not change hierarchical relations. Richards (1997) explained this fact by a combination of Shortest Attract

\footnotetext{
${ }^{28}$ Whether or not the subject of a passive moves first to $\mathrm{v}$ on its way to $\mathrm{T}$. If an object quantifier moves further than $\mathrm{v}$, to $\mathrm{T}$ for instance, the derived subject can reconstruct either to the intermediate position of Johnson and Tomioka 1997 or to v.

${ }^{29}$ An anonymous reviewer points out the following case of frozen inverse scope, from Kuno 1971:365:

(i) There are many girls in every class.

*many > every, every > many

The lack of the surface scope reading follows from the assumptions adopted here, if there-insertion leaves the subject in its base position at v. Every class will be forced to raise to $\mathrm{vP}$ in order to be interpreted, and because the subject cannot move to TP if there is inserted, inverse scope will necessarily result. (As a reviewer points out, this account is predicated on the assumption that "expletive replacement" as in Chomsky 1986b does not take place at LF. To the extent that it has any explanatory power, it is therefore an argument against LF movement of the associate in an existential construction.)
} 
and Shortest Move (Shortest) and showed it to hold generally in all cases of multiple movement. The central hypothesis of this article assimilates QR to these phenomena, claiming that multiple quantifiers originating within the VP can never change their relative scope. Hypothesizing that $\mathrm{QR}$ is an interpretive operation that must make use of syntactic resources - specifically, featuredriven movement-effectively generalizes Shortest to the covert raising of quantifiers (presumably to all syntactic operations). Shortest forces crossing paths in such cases of multiple movement, permitting an explanation for frozen scope that assimilates it to similar phenomena in wh-movement and A-scrambling, as well as in object shift. The behavior of quantifiers in ACD follows from the hypothesis as well. Because Shortest only constrains quantifiers that undergo covert movement of the type under discussion, scope relations between the subject and quantified objects are predicted to be variable. The behavior of quantifiers under passivization is exactly as predicted by this theory, providing strong evidence in its favor.

The notion of feature used to drive quantifier movement is a more general but relativized version of the EPP-features of Chomsky (2000, to appear). Hypothesizing that their presence has effects on and is partially licensed by the semantics permits an indirect relationship between syntactic movement and semantic interpretation, which is exactly what is necessary to explain the only partial ability of QR to change scope relations.

\section{Scope Frozen and Free}

The theory developed above severely restricts the changes in scope relations that QR can effect. Any two quantifiers that both undergo $\mathrm{QR}$ will never be able to reverse their scope. This is a desirable result, since scope is most free to change in cases of quantifier-operator interaction (as in the case of intensional verbs), which Shortest does not (directly) constrain, and in cases of multiple quantifiers when one is a subject. A few words must now be said about the locative variants of spray-load and double object verbs, and PP complements and adjuncts generally. Scope in these cases is free, and it has even been claimed to be much more so than in the interaction between subjects and objects (Pica and Snyder 1994).

A structural difference between the configurations where scope is frozen (complex predicates) and their locative variants is well motivated, as illustrated in the next section. Recent work has shown that the first object in complex-predicate constructions is merged in a higher verbal projection than the second object, while both objects (direct object and locative PP) are merged in the same verbal projection in the locative variants. This difference points the way to understanding the difference between the two with regard to scope. ${ }^{30}$

\subsection{Complex Predicates versus Locatives}

As discussed above, scope is frozen in the double object construction and the with variant of the spray-load alternation, but not in the locative variants of these constructions.

\footnotetext{
${ }^{30}$ Martha McGinnis (personal communication) has pointed out an article by Basilico (1998) that also attempts to deal with the frozen scope facts using different domains in the two constructions. However, that theory, based as it is on Aoun and Li's (1993) Minimal Binding Requirement, also falters when faced with the full range of data, particularly the fact that a second object can take scope over the subject (section 4.2).
} 
(57) a. Ozzy gave a (\#different) girl every telescope.

b. The teacher gave a (different) book to every student.

$$
\begin{aligned}
* \text { every } & >a \\
\text { every } & >a \\
* \text { every } & >a \\
\text { every } & >a
\end{aligned}
$$

(58) a. Maud draped a (\#different) armchair with every sheet.

b. Maud draped a (different) sheet over every armchair.

The theory proposed in the preceding section predicts that wherever c-command relations are unambiguous - wherever computation of Shortest unambiguously picks out a single pair as shortest-scope should be frozen. In contrast, if a structure ever consists in part of two quantified elements that are equivalent in distance from a head with a P-feature, scope should be free. In such a case either element would be able to move first; with respect to neither would there exist a well-formed pair that is smaller. The theory will be supported, then, if a difference in exactly this area can be motivated independently for the two alternants of these constructions.

It so happens that much recent work on argument structure has converged on exactly this difference between the two alternants of spray-load verbs and ditransitives (e.g., Marantz 1993, Pesetsky 1995, Arad 1998). All of these works, though differing in detail, agree that complex predicates involve an extra level of structure that is not present in the locative variant. I will adopt the structure from Marantz 1993, illustrated in (59) for the double object construction. ${ }^{31}$ In (59) the goal argument (the indirect object) is projected by a null verbal head $\left(\mathrm{V}_{1}\right)$ between $\mathrm{v}$ and the lexical verb. The lexical verb, $\mathrm{V}_{2}$ in this structure, moves through this null morpheme on its way to $\mathrm{v}$.

(59) Double object construction (Marantz 1993)

a. The lighting gives me a headache.

b.

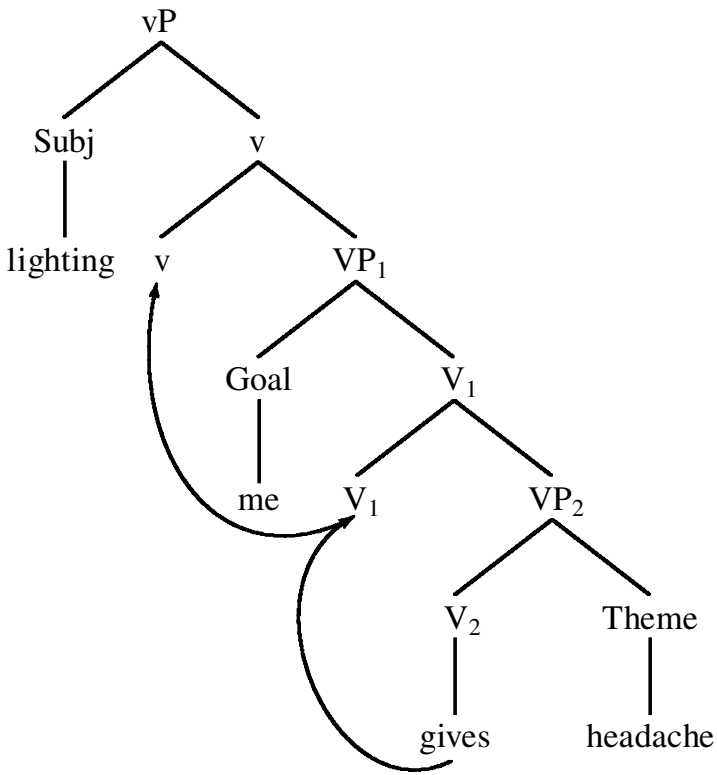

31 The structure advocated by Pesetsky (1995), where the lower argument in complex predicates is introduced by a null preposition that affixes to the verb, will also serve for the purposes of this article. 
Positing the presence of this morpheme accounts for a variety of syntactic and semantic facts crosslinguistically, both in languages that use an overt applicative morpheme (e.g., Bantu languages) and in languages that use a null affix, as in English. One such fact is accounted for by hypothesizing that the null verbal head (as well as its overt applicative cousins in Bantu) introduces the semantics of affectedness. It has been known since Oehrle 1976 that the indirect object in a double object construction receives an affected interpretation that is lacking in its dative counterpart; hence the contrast in $(60 \mathrm{a}-\mathrm{b})$. If the dative lacks the null applicative morpheme, consisting instead only of the lexical verb with a locative prepositional phrase (61), the contrast is explained (the nature of the node labeled "??' will be taken up below).

(60) a. The lighting here gives me a headache.

b. *The lighting here gives a headache to me.

(61) Dative construction

a. John gave a book to Mary.

b.

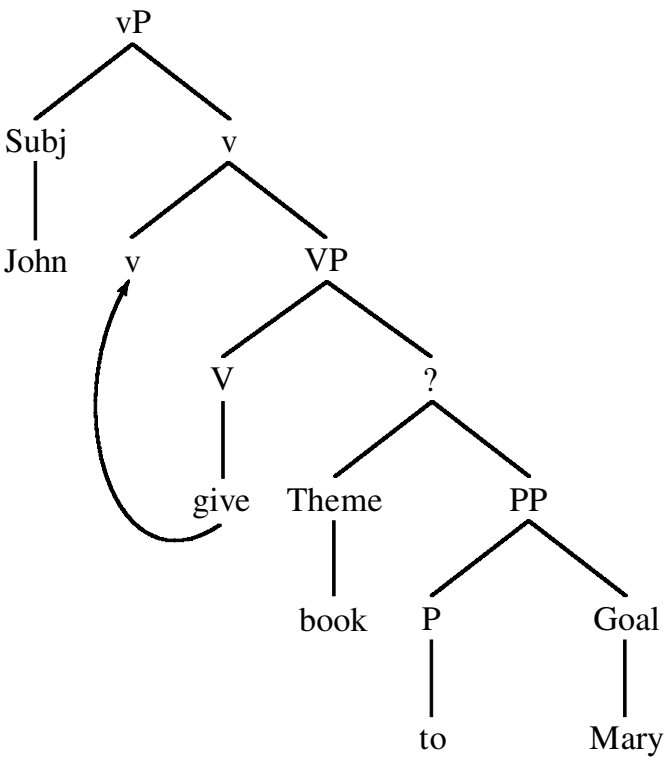

The dative or locative NP can have only a goal, endpoint, or source interpretation: whatever is provided by the preposition alone. Affectedness can only be introduced by the applicative morpheme. Because headaches cannot be transferred like books, (60b) is anomalous.

A second fact explained by the presence of the null applicative morpheme in (59) but its absence in (61) is the lack of double object nominalizations in English (Anderson 1971, Kayne 1984, Pesetsky 1995), as illustrated in (62a).

(62) a. *Sue's gift of Mary (of) a book

b. John's gift of a book to Mary

In contrast, dative nominalizations are perfectly grammatical (62b). If nominalizations of this sort (what Marantz (1997) refers to as "root nominalizations") are prohibited from nominalizing the 
complex of a lexical verb plus applicative morpheme, ${ }^{32}$ the lack of such nominalizations is also explained.

Marantz (1993) further argues that the structure in (59) underlies an entire class of constructions, what he calls (following Larson 1988) "complex predicates.', These include morphological causatives and applicatives in languages such as those of the Bantu family, and the with variants of spray-load verbs in languages like English. The latter involve, in addition to the null applicative affix, a mediating preposition; for example, the two variants of drape would have the structures shown in (63). All verbs matching the description of a complex predicate-the theme is lower than the goal, and scope is frozen - also lack root nominalizations (64) (Pesetsky 1995), whether or not they alternate (see footnote 4 ).

(63) With variant (complex predicate)

a. i. Maud draped the chair with cloth.

ii.

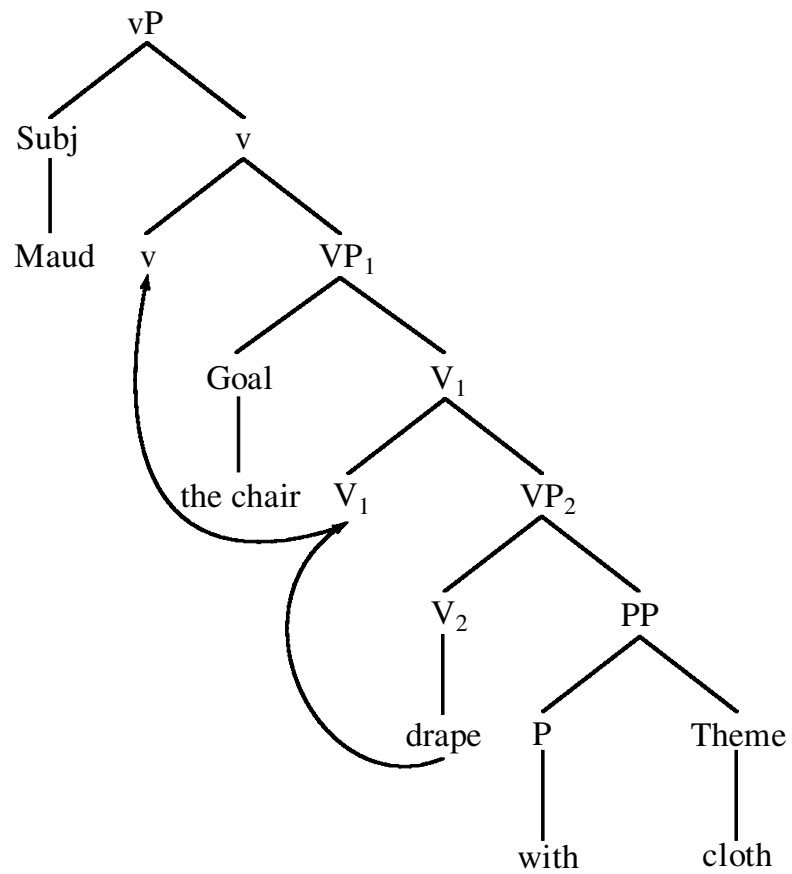

${ }^{32}$ This is the content of Myers's Generalization (Myers 1984); see Pesetsky 1995 for extensive discussion. 


\section{Over variant (locative)}

b. i. Maud draped cloth over the chair.

ii.

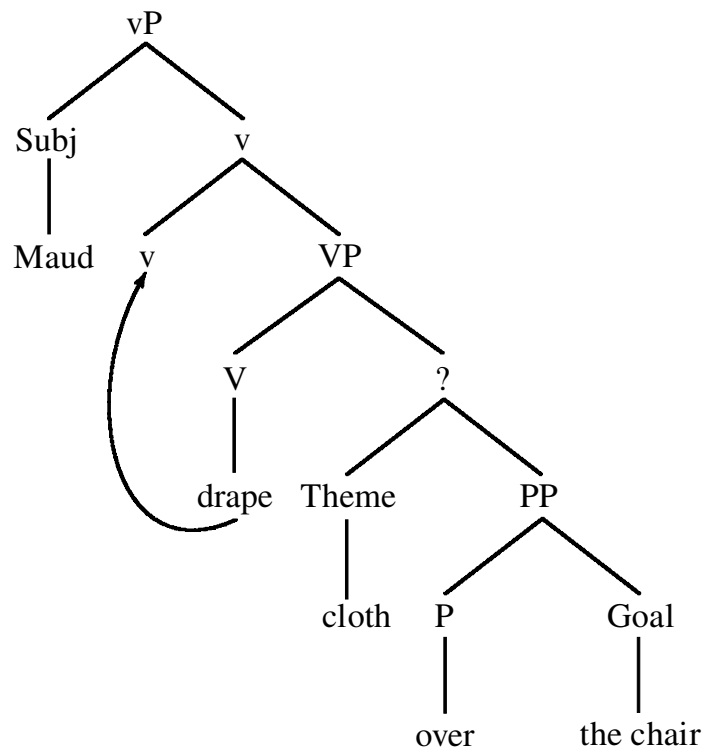

(64) a. The general presented a plan to the admiral.

b. The general presented the admiral with a plan.

c. the general's presentation of a plan to the admiral

d. *the general's presentation of the admiral with a plan

The frozen variants of the spray-load verbs pattern with the double object construction in other ways as well, such as the inability of the first object to act as the subject of a secondary predicate (Hale and Keyser 1997, Gruber 2000).

Further evidence for two domains (i.e., two verbal projections) in the complex predicate but only one in the locative construction comes from a variety of sources: phonological phrasing and the position of adverbial phrases in Chinese (Soh 1998), object asymmetries in Bantu languages (Marantz 1993, Seidl 1999), and numerous other facts.

\subsection{Shortest in Complex Predicates and Locatives}

Once we have the structures in (59) and (61), we have the ability to explain the existence of frozen scope in complex predicates but not in locative constructions. In the former, as shown in (59), the first object asymmetrically c-commands the second (as shown by binding facts: Barss and Lasnik 1986, Larson 1988, Pesetsky 1995) and will always be attracted to v first. That is, there will always be a well-formed pair consisting of the first object and $\mathrm{v}$ that will prevent attraction of the second object. Asymmetric c-command follows from the proposed structure: the first object is an argument of the higher applicative head and is merged in a projection above the 
VP into which is merged the second object. The two objects are arguments of different heads in this theory.

In contrast, the two objects in the locative construction are arguments of the same head and are merged into the same verbal projection, as indicated in (61). While binding tests show that the direct object in these constructions c-commands the object of the preposition and not vice versa (Barss and Lasnik 1986, Pesetsky 1995, Phillips 1996), the direct object and the PP might both c-command each other. If covert QR can pied-pipe the PP, then, moving either the direct object or the PP first will obey Shortest, since each c-commands the other.

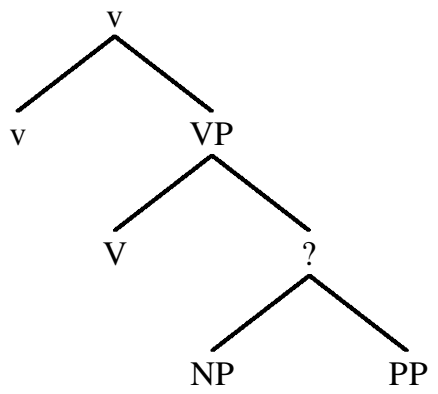

The pairs $\{\mathrm{v}, \mathrm{NP}\}$ and $\{\mathrm{v}, \mathrm{PP}\}$ are equivalent; hence, both satisfy Shortest.

Some observations regarding Superiority in $w h$-questions indicate that this approach is on the right track. My investigations reveal that there is a contrast between stranding the preposition in wh-movement and pied-piping, although the judgments are complicated by the fact that many speakers disprefer overt pied-piping (particularly in indirect questions). Every speaker I have consulted, however, finds a contrast between the (b) and (c) examples of (66)-(67). ${ }^{33}$

(66) a. What did you send to who?

b. *Who did you send what to?

c. ?To who(m) did you send what?

(67) a. What do you think he sent to who?

b. *Who do you think he sent what to?

c. ?To whom do you think he sent what?

As is predicted by the structural difference between complex predicates and locatives, pied-piping in the spray-load alternation does not help at all. ${ }^{34}$

${ }^{33}$ Judgments of Superiority reported in the literature for such cases conflict. For example, Larson (1988) states that both pied-piping and preposition stranding induce Superiority effects (*Whom did you send which check to? and *To whom did you send which check?), while Berman and Hestvik (1991) claim that Superiority does not hold in locative constructions with pied-piping (What did John give to whom? and To whom did John give what? are equally grammatical).

${ }^{34}$ Norvin Richards (personal communication) points out the following contrast noted by Chomsky (1986a:39):

(i) a. *Who did you wonder what John gave to?

b. ?To whom did you wonder what John gave?

The theory advocated here makes an explanation of this contrast available: if the entire PP but not the object of the preposition can underg o $w h$-movement prior to the direct object, it will not violate Superiority (and might not even violate 
(68) a. Who did you spray with what?

b. *What did you spray who with?

c. *With what did you spray who?

(69) a. Who do you think Bill sprayed with what?

b. *What do you think Bill sprayed who with?

c. *With what do you think Bill sprayed who?

If this is correct, it is plausible to suppose that covert QR can pied-pipe the entire PP. That is, the entire PP must count as a quantifier for Attract, in the same way as an entire PP must count as a $w h$-phrase for $w h$-movement. C-command between a direct object and a PP in the locative configuration is mutual (but it is not in the complex predicate construction), which will permit either to move to $\mathrm{v}$ first under attraction. Thus, the ambiguity of the locative construction follows from the theory, given the independently motivated structure of this construction.

Another indication that this is the correct explanation of ambiguity in the locative comes from locative inversion, in which the PP advances to subject in a passive clause (e.g., Kuno 1971, Emonds 1976, Hoekstra and Mulder 1990, Bresnan 1994, Levin and Rappaport Hovav 1995).

(70) a. Over every armchair was draped a sheet.

b. To Bill was given the collection of grandfather clocks.

If movement to TP is constrained by Shortest in the same way as all other movement, the existence of locative inversion argues that the locative PP and the theme NP mutually c-command each other, since either can advance to subject position in the passive. ${ }^{35}$

\subsection{The Structure of the Locative}

The structure shown in (61) left open the nature of the node dominating the theme NP and the goal PP. One possibility consonant with much recent work is that the theme NP and the PP form a "small clause" constituent in which the NP is the specifier of PP (Stowell 1981, 1983, Kayne 1984), as shown in (71). In this structure $a$ book is the subject of a predicate to Mary (Hoekstra and Mulder 1990, Den Dikken 1995; cf. Harley 1995). If this structure is correct, it must somehow be ensured that movement operations target the node labeled ' $\mathrm{P}$ ', ' to the exclusion of the NP a book, since it is this constituent that moves in locative inversion, in $w h$-movement, and in other instances of movement. (See the extensive literature on this topic, e.g., Manzini 1983, Hornstein and Lightfoot 1987, Koopman and Sportiche 1991, Huang 1993. Cf. 'P-splitting', in Pesetsky 1995 and Phillips 1996.)

the ban on extraction from a wh-island). Note that, as predicted, the with variant of spray-load verbs does not improve with pied-piping in this environment.

(ii) a. *What did you wonder who John sprayed with?

b. *With what did you wonder who John sprayed?

${ }^{35}$ Note that agreement is always with the theme (To Bill were given all the old grandfather clocks), which would follow from the operation Agree being restricted to NPs. 
(71)

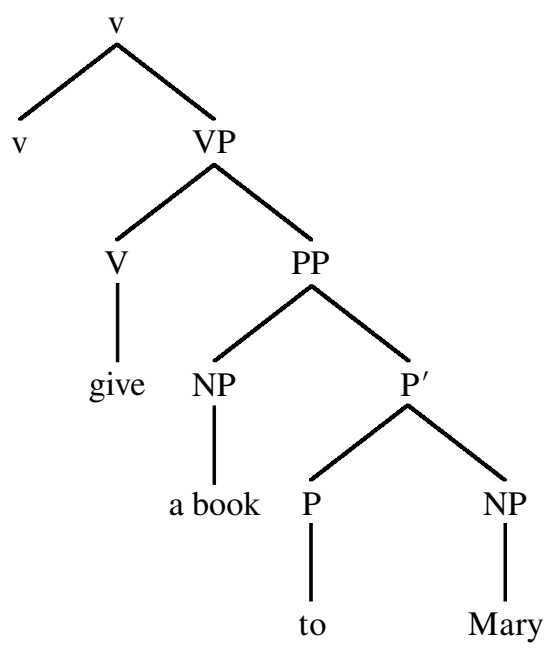

A second alternative is a ternary-branching structure, where the node "?" is actually VP.

(72)

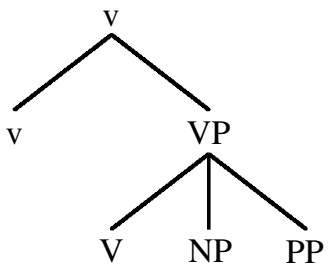

This structure, although it makes the right predictions for binding and movement (at least the types of movement discussed here), is ruled out by theoretical principles in most current approaches to syntax (though it is not by that token incorrect).

The available evidence does not decide on the exact structure, and I will leave it open here; what is crucial is that NP and PP are sisters in the same domain in the locative but not in complexpredicate constructions.

A quite different approach to ambiguity in the dative is that argued for by Pesetsky (1995) and Takano (1998), involving crossover and connectivity. On this approach the theme moves overtly across the goal PP in locative constructions, being projected originally below it. By connectivity (Barss 1986) or reconstruction, it is able to reconstruct to a position below the PP as far as scope is concerned.

(73) I gave [a different book] to every student $t_{\text {theme }}$.

reconstruction

While there are some arguments for this movement of themes (chiefly from backward binding of reciprocals: I showed each other's houses to John and Mary), it is also problematic, particularly from the point of view of interpretation. On the view advocated here, a quantifier would not be interpretable in a position below the PP and should therefore be unable to reconstruct to that 
position. In addition, the Superiority account of scope freezing relies on the inability of QR to reconstruct (only non-scope-taking movement, such as EPP movement to TP, can). If reconstruction back within the VP were possible, there could be no scope freezing.

However, Sauerland (2000) argues for a version of crossover movement that gets around these problems, using the PF movement approach to reconstruction developed in Sauerland and Elbourne 1999. In this version the theme may move to its surface position at PF only, staying in its base position in the syntax proper. At LF the syntactic object in base position will raise to an interpretable position at vP. At the beginning of the LF cycle, however, it is lower than the PP and hence will be forced to move after it, by Shortest. This sequence of movements is illustrated in $(74){ }^{36}$

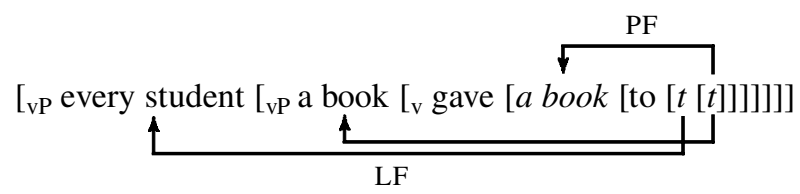

On the other scope reading, where the theme takes scope over the PP goal, the movement of the theme takes place in the syntax, not just at PF. At the beginning of the LF cycle, then, the theme is higher than the goal and will be forced to undergo QR first, by Shortest.

\section{The Nature of QR}

Throughout this article I have implicitly (or explicitly) adopted the view (from May 1977) that QR applies to all and only quantifiers, and moreover that movement beyond the first step to vP is available (if it would change scope relations) but optional (unless forced by ACD). In contrast, several recent theories argue that QR is driven by formal features, in a way different from that outlined here. In this section I examine the implications that the data presented here have for such approaches. The conclusion is that these proposals are untenable.

\subsection{QR versus Case Movement}

In contrast to the point of view adopted here, some authors have argued that what has been taken to be QR is actually an independent and general movement of arguments, namely, movement to Agr(eement) projections for Case-checking reasons (see Hornstein 1994, 1995, Lasnik 1993, Pica and Snyder 1994, Schmitt 1995). One might wonder if the ordering account developed here could be recast in more recent minimalist proposals (e.g., Chomsky 2000) that do away with Agr

\footnotetext{
${ }^{36}$ There are still problems with the crossover account. One is that genuine cases of crossover do not permit direct binding of the crossed NP by the moved NP (Rizzi's (1986) Chain Condition; see also McGinnis 1998), but this is perfectly possible in the dative: I showed John to himself. There also appears to be a generalization that elements that undergo movement cannot be extracted from: for instance, exceptional-Case-marking subjects and subjects in TP (but not $\mathrm{vP}$, as in existentials). But the theme in the locative can be extracted from easily: Which chocolate bar did you give a piece of to Susie?
} 
projections and raise all arguments to v (as in Richards's (1997) proposal for “'Agr $\forall \mathrm{P}$ '). Since all arguments raise to the same position, Shortest would apply and force them to cross paths.

There are two points to make. The first is that, as Kennedy (1997) shows, A-movement theories of QR are inadequate to account for many instances of ACD_for example, cases of ACD in PPs and inside complex NPs, where most theories do not posit Case-checking movements. Similarly, ACD is possible where QR would be required across multiple embeddings (e.g., Marie wants to start to make every change in lifestyle that I do), a context where A-movement is generally taken to be impossible. In addition, the A-movement account completely misses the generalization, laid out above, that the acceptability of ACD correlates perfectly with the availability of (often mandatory) wide scope.

The second point concerns the obviation of Condition C in ACD. Fox (1995a), using observations from Fiengo and May 1994, has argued that ACD bleeds Condition C, so that movement of a quantifier for ACD resolution can alleviate violations of Condition $\mathrm{C}$.

(75) a. I reported $\operatorname{him}_{1}$ to every cop that $\mathrm{John}_{1}$ was afraid I would [VP $\Delta$ ].

b. ??I reported $\operatorname{him}_{1}$ to every cop that $\mathrm{John}_{1}$ was afraid of.

QR moves the R-expression John (contained in the universal quantifier) across the pronoun him, with the result that the latter no longer c-commands the former. Condition $\mathrm{C}$ is no longer violated, and the sentence is fully grammatical. In contrast, a similar sentence without ACD is deviant because of the coreference indicated (75b). ${ }^{37}$ If QR were just a general movement for Case, pronouns would move as well as quantifiers, and the account of the circumvention of Condition C would be lost. ${ }^{38}$

Case-driven movement is therefore both too general (moving nonquantifiers as well as quantifiers) and too restrictive (not applying in cases where QR must be posited). The P-feature analysis advocated here, while similar in uniting all movement as feature-driven, avoids both errors.

\subsection{DistP}

The data presented here bear on another recent theory of scopal interactions, that of Beghelli (1996) and Beghelli and Stowell (1996). In this theory distributive readings for the "strongly

${ }^{37}$ Note that Condition $\mathrm{C}$ effects also disappear in the double object construction.

(i) a. I sent $\operatorname{him}_{1}$ the book that $\mathrm{John}_{1}$ asked me to [vP $\Delta$ ].

b. ??I sent him 1 the book that $\mathrm{John}_{1}$ asked me to write.

This would be a problem for Fox's account of the Condition C effect, but on the present theory it is just a subcase of the relative nature of scope freezing. The second object, if a quantifier, will necessarily cross over the first if the latter is nonquantificational. It is only when the first object is a quantifier that the second is restricted in its movements. Thus, Fox's explanation for the Condition $\mathrm{C}$ effects can be maintained without modification under the present hypothesis.

${ }^{38}$ The reason ACD is required to obviate Condition C, according to Fox, lies in the way chains are interpreted. In cases of QR without ACD, as in I sent him every book that John asked me to write, all that is required for interpretation is that the quantifier move over the pronoun to vP. Its restriction need not move and hence must not, by Economy; it can be interpreted in situ. In ACD, on the other hand, the only way to produce a convergent derivation is to pied-pipe the restriction with the quantifier. However, I do not find coreference particularly ungrammatical in I sent him every book that John asked me to write; Kennedy (1997:fn. 22) reports a similar judgment. 
distributive"' quantifiers each and every arise by movement of the quantified NPs to a head, Dist, which is responsible for the semantics of distributivity. Group-denoting quantifiers like some, one, and the and cardinal expressions like few and at least do not move to Dist; instead, they move to other heads that provide different interpretations.

Beghelli and Stowell claim that distributive readings arise with the distributive universal quantifier each in any syntactic configuration (but only in some circumstances with every), indicating that it is not its relation to other quantifiers that provides a distributive reading. This is the motivation for a distinct operator contributing the semantics of distributivity. But the facts uncovered here show that this is not the case. First, distributive readings with each, as well as every, are entirely lacking in frozen scope environments. The choice of quantifier for the first object does not matter; each as a second object is simply unable to take wide scope or to acquire a distributive reading. Yet all the evidence amassed here indicates that each can still move from object position in these constructions. So it cannot be the case that each in double object constructions is simply prevented from reaching the Dist head by constraints on movement.

In fact, all the evidence suggests that quantifiers act much alike with regard to movement from all syntactic positions, at least for the first step to vP. The initial step, and subsequent steps in ACD, have to be available even to group-denoting quantifiers, which Beghelli and Stowell argue do not undergo movement.

(76) I want to buy one CD that you do [vp want to buy].

In this example, if the ellipsis is interpreted as including want, as shown, one must be interpreted de re (taking scope over want). It therefore appears that group-denoting QPs can move at least as far as successive instances of $\mathrm{v}$.

These considerations suggest that the DistP theory is incorrect. Instead, something like a mixed syntactic-semantic account of distributive readings, whereby they arise through quantifierquantifier interaction, is more tenable. The fact that each and every can never take scope over the first object when scope is frozen would then explain why a distributive reading is unavailable.

\section{Conclusion}

QR has from one point of view always been something of a mysterious operation, since it does not seem to be subject to the same sorts of constraints operable in more visible movements like wh-movement. I have shown here that this is not the case: exactly the same constraints on movement operate to constrain $\mathrm{QR}$. These are general economy constraints that are evaluated locally, without look-ahead, at each point where an operation might apply.

The proposed theory not only unifies QR and most other instances of movement, it also accounts for cases of scope ambiguity — which arise only in a restricted range of circumstances - and otherwise mysterious instances of a lack of ambiguity (frozen scope). Moreover, the data presented here indicate that A-movement accounts of $\mathrm{QR}$ are inadequate and that feature attraction as it has been implemented previously cannot account for frozen scope and its behavior in ACD. In contrast, the way of viewing QR presented here, where $\mathrm{QR}$ is feature-driven in mechanism but interpretive in nature, accounts for the apparent driving force of semantics as well 
as the semantics' inability to effect certain syntactic changes. If semantic interpretation is mediated by optional features in the same way as object shift, the facts fall neatly into place as part of Richards's generalization.

In addition, the Superiority account of frozen scope makes many testable predictions, which were not explored here for reasons of space. Shortest should make its effects on QR felt in constructions and configurations outside of ditransitive VPs - for instance, across clause boundaries (as in verbs of perception; see Pica and Snyder 1994) and inside complex NPs. ${ }^{39}$

\section{References}

Anderson, Stephen R. 1971. On the role of deep structure in semantic interpretation. Foundations of Language 7:387-396.

Anderson, Stephen R. 1977. Comments on the paper by Wasow. In Formal syntax, ed. Peter Culicover, Thomas Wasow, and Adrian Akmajian, 361-377. New York: Academic Press.

Aoun, Joseph, and Yen-hui Audrey Li. 1989. Constituency and scope. Linguistic Inquiry 20:141-172.

Aoun, Joseph, and Yen-hui Audrey Li. 1993. Syntax of scope. Cambridge, Mass.: MIT Press.

Arad, Maya. 1998. VP-structure and the syntax-lexicon interface. Doctoral dissertation, University College London. [Reprinted as MIT Occasional Papers in Linguistics 16. MITWPL, Department of Linguistics and Philosophy, MIT, Cambridge, Mass.]

Barss, Andrew. 1986. Chains and anaphoric dependence: On reconstruction and its implications. Doctoral dissertation, MIT, Cambridge, Mass.

Barss, Andrew, and Howard Lasnik. 1986. A note on anaphora and double objects. Linguistic Inquiry 17: 347-354.

Barwise, Jon, and Robin Cooper. 1981. Generalized quantifiers and natural language. Linguistics and Philosophy 4:159-219.

Basilico, David. 1998. Object position and predication forms. Natural Language \& Linguistic Theory 16: 541-595.

Beghelli, Filippo. 1996. The syntax of distributivity and pair-list readings. In Ways of scope taking, ed. Anna Szabolcsi, 349-408. Dordrecht: Kluwer.

Beghelli, Filippo, and Tim Stowell. 1996. Distributivity and negation: The syntax of each and every. In Ways of scope taking, ed. Anna Szabolcsi, 71-107. Dordrecht: Kluwer.

Berman, Steve, and Arild Hestvik. 1991. LF: A critical survey. Stuttgart: Universität Stuttgart.

Bošković, Željko. 1995. Superiority effects with multiple $w h$-fronting in Serbo-Croatian. Ms., University of Connecticut, Storrs.

Bouton, Lawrence. 1970. Antecedent contained proforms. In Papers from the Sixth Regional Meeting of the Chicago Linguistic Society, 154-167. Chicago Linguistic Society, University of Chicago, Chicago, Ill.

Bresnan, Joan. 1994. Locative inversion and the architecture of Universal Grammar. Language 70:72-131.

Chierchia, Gennaro. 1993. Questions with quantifiers. Natural Language Semantics 1:181-234.

Chomsky, Noam. 1973. Conditions on transformations. In A festschrift for Morris Halle, ed. Stephen R. Anderson and Paul Kiparsky, 232-286. New York: Holt, Rinehart and Winston. [Reprinted in Noam Chomsky, Essays on form and interpretation, 81-160. New York: North-Holland (1977).]

Chomsky, Noam. 1986a. Barriers. Cambridge, Mass.: MIT Press.

Chomsky, Noam. 1986b. Knowledge of language: Its nature, origin, and use. New York: Praeger.

\footnotetext{
${ }^{39}$ For further application of the idea that QR is subject to Superiority, see the account of inverse linking in nominals in Sauerland 2000.
} 
Chomsky, Noam. 1993. A minimalist program for linguistic theory. In The view from Building 20: Essays in linguistics in honor of Sylvain Bromberger, ed. Kenneth Hale and Samuel Jay Keyser, 1-52. Cambridge, Mass.: MIT Press.

Chomsky, Noam. 1995. Categories and transformations. In The Minimalist Program, 219-394. Cambridge, Mass.: MIT Press.

Chomsky, Noam. 2000. Minimalist inquiries: The framework. In Step by step, ed. Roger Martin, David Michaels, and Juan Uriagereka, 89-155. Cambridge, Mass.: MIT Press. [Also available as MIT Occasional Papers in Linguistics 15, MITWPL, Department of Linguistics and Philosophy, MIT, Cambridge, Mass.]

Chomsky, Noam. To appear. Derivation by phase. In Ken Hale: A life in language, ed. Michael Kenstowicz. Cambridge, Mass.: MIT Press.

Collins, Chris. 1997. Local economy. Cambridge, Mass.: MIT Press.

Collins, Chris, and Höskuldur Thráinsson. 1996. VP-internal structure and object shift in Icelandic. Linguistic Inquiry 27:391-444.

Dikken, Marcel den. 1995. Particles: On the syntax of verb-particle, triadic, and causative constructions. Oxford: Oxford University Press.

Dikken, Marcel den, and René Mulder. 1991. Double object scrambling. In MIT working papers in linguistics 14: Papers from the Third Student Conference in Linguistics, 67-82. MITWPL, Department of Linguistics and Philosophy, MIT, Cambridge, Mass.

Emonds, Joseph. 1976. A transformational approach to English syntax. New York: Academic Press.

Falk, Cecilia. 1990. On double object constructions. Working Papers in Scandinavian Syntax 46:53-100.

Fiengo, Robert, and Robert May. 1994. Indices and identity. Cambridge, Mass.: MIT Press.

Fillmore, Charles J. 1968a. The case for case. In Universals in linguistic theory, ed. Emmon Bach and R. T. Harms, 1-88. New York: Holt, Rinehart and Winston.

Fillmore, Charles J. 1968b. Lexical entries for verbs. Foundations of Language 4:373-393.

Fox, Danny. 1995a. Condition C effects in ACD. In MIT working papers in linguistics 27: Papers on minimalist syntax, 105-119. MITWPL, Department of Linguistics and Philosophy, MIT, Cambridge, Mass.

Fox, Danny. 1995b. Economy and scope. Natural Language Semantics 3:283-341.

Fox, Danny. 2000. Economy and semantic interpretation. Cambridge, Mass.: MIT Press and MITWPL.

Gruber, Jeffrey S. 2000. Thematic relations in syntax. In A handbook of contemporary syntactic theory, ed.

Mark R. Baltin and Chris Collins, 257-298. Oxford: Blackwell.

Haegeman, Liliane. 1993. The morphology and distribution of object clitics in West Flemish. Studia Linguistica 47:57-94.

Haegeman, Liliane. 1996. The typology of syntactic positions: L-relatedness and the A/A' distinction. In Minimal ideas: Syntactic studies in the minimalist framework, ed. Werner Abraham, Samuel David Epstein, Höskuldur Thráinsson, and C. Jan-Wouter Zwart, 141-165. Amsterdam: John Benjamins.

Haegeman, Liliane, and Raffaella Zanuttini. 1991. Negative heads and the Neg Criterion. The Linguistic Review 8:233-251.

Hale, Ken, and Samuel Jay Keyser. 1997. On the double-object construction. Ms., MIT, Cambridge, Mass. Hall, Barbara. 1965. Subject and object in Modern English. Doctoral dissertation, MIT, Cambridge, Mass. Harley, Heidi. 1995. Subjects, events, and licensing. Doctoral dissertation, MIT, Cambridge, Mass.

Heim, Irene, and Angelika Kratzer. 1998. Semantics in generative grammar. Oxford: Blackwell.

Higginbotham, James. 1980. Pronouns and bound variables. Linguistic Inquiry 11:679-708.

Hoekstra, Teun, and René Mulder. 1990. Unergatives as copular verbs: Locational and existential predication. The Linguistic Review 7:1-79.

Hornstein, Norbert. 1994. An argument for minimalism: The case of antecedent-contained deletion. Linguistic Inquiry 25:455-480. 
Hornstein, Norbert. 1995. Logical Form: From GB to minimalism. Cambridge, Mass.: Blackwell. Hornstein, Norbert, and David Lightfoot. 1987. Predication and PRO. Language 63:23-52.

Huang, C.-T. James. 1993. Reconstruction and the structure of VP: Some theoretical consequences. Linguistic Inquiry 24:103-138.

Johnson, Kyle. 1991. Object positions. Natural Language \& Linguistic Theory 9:577-636.

Johnson, Kyle, and Satoshi Tomioka. 1997. Lowering and mid-size clauses. In Proceedings of the Tübingen Workshop on Reconstruction, 177-198. Universität Tübingen.

Kayne, Richard. 1984. Connectedness and binary branching. Dordrecht: Foris.

Kennedy, Christopher. 1997. Antecedent-contained deletion and the syntax of quantification. Linguistic Inquiry 28:662-688.

Kitahara, Hisatsugu. 1994. Restricting unambiguous rule-application: A unified analysis of movement. In MIT working papers in linguistics 24: Formal Approaches to Japanese Linguistics I, 179-209. MITWPL, Department of Linguistics and Philosophy, MIT, Cambridge, Mass.

Kitahara, Hisatsugu. 1995. Target $\alpha$ : Deducing strict cyclicity from derivational economy. Linguistic Inquiry 26:47-77.

Kitahara, Hisatsugu. 1996. Raising quantifiers without quantifier raising. In Minimal ideas: Syntactic studies in the minimalist framework, ed. Werner Abraham, Samuel David Epstein, Höskuldur Thráinsson, and C. Jan-Wouter Zwart, 189-198. Amsterdam: John Benjamins.

Kitahara, Hisatsugu. 1997. Elementary operations and optimal derivations. Cambridge, Mass.: MIT Press. Koopman, Hilda, and Dominique Sportiche. 1991. The position of subjects. Lingua 85:211-258.

Kratzer, Angelika. 1996. Severing the external argument from its verb. In Phrase structure and the lexicon, ed. Johan Rooryck and Laurie Zaring, 109-137. Dordrecht: Kluwer.

Kratzer, Angelika. 1998. Scope or pseudoscope: Are there wide-scope indefinites? In Events and grammar, ed. Susan Rothstein, 163-196. Dordrecht: Kluwer.

Kuno, Susumu. 1971. The position of locatives in existential sentences. Linguistic Inquiry 2:333-378.

Larson, Richard K. 1988. On the double object construction. Linguistic Inquiry 19:335-391.

Larson, Richard K. 1990. Double objects revisited: Reply to Jackendoff. Linguistic Inquiry 21:589-632.

Larson, Richard K., and Robert May. 1990. Antecedent containment or vacuous movement: Reply to Baltin. Linguistic Inquiry 21:103-122.

Lasnik, Howard. 1993. Lectures on minimalist syntax. UConn Occasional Papers in Linguistics 1. MITWPL, Department of Linguistics and Philosophy, MIT, Cambridge, Mass.

Levin, Beth. 1993. English verb classes and alternations. Chicago: University of Chicago Press.

Levin, Beth, and Malka Rappaport Hovav. 1995. Unaccusativity: At the syntax-lexical semantics interface. Cambridge, Mass.: MIT Press.

Manzini, Maria Rita. 1983. Restructuring and reanalysis. Doctoral dissertation, MIT, Cambridge, Mass.

Marantz, Alec. 1993. Implications of asymmetries in double object constructions. In Theoretical aspects of Bantu grammar, ed. Sam A. Mchombo, 113-150. Stanford, Calif.: CSLI Publications. [Distributed by Cambridge University Press.]

Marantz, Alec. 1997. No escape from syntax: Don't try morphological analysis in the privacy of your own lexicon. In Proceedings of the 21st Annual Penn Linguistics Colloquium, Penn Working Papers in Linguistics 4.2, 201-225. Penn Linguistics Circle, University of Pennsylvania, Philadelphia.

May, Robert. 1977. The grammar of quantification. Doctoral dissertation, MIT, Cambridge, Mass.

May, Robert. 1985. Logical Form. Cambridge, Mass.: MIT Press.

May, Robert. 1988. Ambiguities of quantification and wh: A reply to Williams. Linguistic Inquiry 19: $118-135$.

McGinnis, Martha. 1998. Locality in A-movement. Doctoral dissertation, MIT, Cambridge, Mass.

Miyagawa, Shigeru. 1997. Against optional scrambling. Linguistic Inquiry 28:1-25. 
Myers, Scott. 1984. Zero-derivation and inflection. In MIT working papers in linguistics 7: Papers from the January 1984 MIT Workshop on Morphology, 53-69. MITWPL, Department of Linguistics and Philosophy, MIT, Cambridge, Mass.

Neeleman, Ad. 1994. Scrambling as a D-Structure phenomenon. In Studies on scrambling: Movement and non-movement approaches to free word-order phenomena, ed. Norbert Corver and Henk van Riemsdijk, 387-429. Berlin: Mouton de Gruyter.

Oehrle, Richard. 1976. The grammatical status of the English dative alternation. Doctoral dissertation, MIT, Cambridge, Mass.

Pesetsky, David. 1995. Zero syntax: Experiencers and cascades. Cambridge, Mass.: MIT Press.

Pesetsky, David. 2000. Phrasal movement and its kin. Cambridge, Mass.: MIT Press.

Phillips, Colin. 1996. Order and structure. Doctoral dissertation, MIT, Cambridge, Mass.

Pica, Pierre, and William Snyder. 1994. Weak crossover, scope, and agreement in a minimalist framework. In Proceedings of the 13th West Coast Conference on Formal Linguistics, 334-349. Stanford, Calif.: CSLI Publications. [Distributed by Cambridge University Press.]

Reinhart, Tanya. 1997. Quantifier scope: How labor is divided between QR and choice functions. Linguistics and Philosophy 20:335-397.

Richards, Norvin. 1997. What moves where when in which language? Doctoral dissertation, MIT, Cambridge, Mass.

Rizzi, Luigi. 1986. On chain formation. In Syntax and semantics 19: The syntax of pronominal clitics, ed. Hagit Borer, 65-95. New York: Academic Press.

Rizzi, Luigi. 1990. Relativized Minimality. Cambridge, Mass.: MIT Press.

Rudin, Catherine. 1988. On multiple questions and multiple WH fronting. Natural Language \& Linguistic Theory 6:445-501.

Sag, Ivan. 1976. Deletion and Logical Form. Doctoral dissertation, MIT, Cambridge, Mass.

Sauerland, Uli. 2000. Syntactic economy and quantifier raising. Ms., Universität Tübingen.

Sauerland, Uli, and Paul Elbourne. 1999. Total reconstruction, PF-movement, and derivational order. Ms., Universität Tübingen and MIT, Cambridge, Mass.

Schmitt, Cristina. 1995. Antecedent contained deletion meets the copy theory. In NELS 25, 425-439. GLSA, University of Massachusetts, Amherst.

Seidl, Amanda. 1999. Object asymmetries and their morphophonological reflexes. In Proceedings of the 18th West Coast Conference on Formal Linguistics, 490-505. Somerville, Mass.: Cascadilla Press.

Soh, Hooi-Ling. 1998. Object scrambling in Chinese. Doctoral dissertation, MIT, Cambridge, Mass.

Sportiche, Dominique. 1996. Clitic constructions. In Phrase structure and the lexicon, ed. Johan Rooryck and Laurie Zaring, 213-276. Dordrecht: Kluwer.

Stowell, Tim. 1981. Origins of phrase structure. Doctoral dissertation, MIT, Cambridge, Mass.

Stowell, Tim. 1983. Subjects across categories. The Linguistic Review 2:285-312.

Stroik, Thomas. 1996. Minimalism, scope, and VP structure. Thousand Oaks, Calif.: Sage.

Takano, Yuji. 1998. Object shift and scrambling. Natural Language \& Linguistic Theory 17:817-889.

Williams, Edwin. 1988. Is LF distinct from S-Structure? A reply to May. Linguistic Inquiry 19:135-146.

Wurmbrand, Susanne. 1998. Infinitives. Doctoral dissertation, MIT, Cambridge, Mass.

Department of Linguistics

E39-245

MIT

77 Massachusetts Avenue

Cambridge, Massachusetts 02139

muawiya@mit.edu 